Part of Journal of Research of the National Bureau of Standards, Volume 26, June 1941

\title{
DETERMINATION OF FREEZING POINTS AND AMOUNTS OF IMPURITY IN HYDROCARBONS FROM FREEZING AND MELTING CURVES ${ }^{*} *$
}

\author{
By Beveridge J. Mair, ${ }^{2}$ Augustus R. Glasgow, Jr., ${ }^{2}$ and Frederick D. Rossini
}

\section{ABSTRACT}

Simple time-temperature freezing and melting curves are analyzed, and a procedure is outlined for determining from them the freezing point of a given substance and the amount of impurity in it. The procedure was applied to a number of different known solutions of hydrocarbons ranging from 0.006 to 0.115 mole fraction in concentration of solute. For the systems examined, it was found that the values for the freezing point of a given substance obtained from both freezing and melting curves were always in accord within their respective limits of uncertainty, and that the estimated amount of impurity was in error by not more than about 10 percent of itself, on the average.

\section{CONTENTS}

I. Introduction

Page

II. Theoretical part _._.

1. Thermodynamic relation involved _... $\ldots \ldots \ldots \ldots \ldots \ldots \ldots \ldots 2$

2. Determination of the freezing point

3. Estimation of the amount of impurity $\ldots \ldots \ldots \ldots . \ldots 5$

III. Experimental part _...

1. Apparatus _...

2. Attainment of equilibrium $\ldots \ldots \ldots \ldots$

3. Determination of the freezing point $\ldots \ldots \ldots \ldots \ldots 6$

4. Estimation of the amount of impurity _...

IV. Conclusion

V. References_.

\section{INTRODUCTION}

In the work of the American Petroleum Institute Research Project 6 at this Bureau on the isolation and identification of hydrocarbons from petroleum, the freezing point of the "best" lot of each hydrocarbon has usually been determined by means of time-temperature freezing or melting curves, and the purity of it has usually been estimated from time-temperature freezing curves according to the method proposed by W. P. White [1]. ${ }^{3}$ In order to check the reliability of such measurements and their interpretation, the authors

\footnotetext{
1 This investigation is part of the work of Research Project 6 of the American Petroleum Institute, from whose research fund financial assistance has been received.

2 Research Associate at the National Bureau of Standards, representing the American Petroleum Institute.

*Presented before the Division of Petroleum Chemistry of the American Chemical Society at St. Louis, Mo., April 8, 1941.

3 Figures in brackets indicate the literature references at the end of this paper.
} 
have examined critically the principles and assumptions involved, and have made experimental observations on several hydrocarbon preparations (solutions) containing different known amounts of impurity (solute).

There are presented herewith the results of this study on the interpretation of time-temperature freezing and melting curves, together with a procedure for obtaining the proper value for the freezing point of a given substance (solution) and a reasonably reliable estimate of the amount of liquid-soluble, solid-insoluble impurity (solute) in it. From these values may be estimated the freezing point of the given substance when it contains no impurity. The apparatus and procedure are relatively simple and may be readily adjusted for observations on compounds having greatly different freezing points. With respect to the impurity in compounds of low impurity, the sensitivity is about 0.0001 mole fraction.

The authors wish to emphasize the fact that methods are available for determining, more accurately than is possible with the simple apparatus and procedure described in this paper, the freezing point of a substance, or the amount of impurity in it, or both. With a calorimetric assembly of the type used in the accurate measurement of heats of fusion and transition, and heat capacities of both the liquid and solid states, observations may be made of the temperature of equilibrium corresponding to various fractions of the substance melted. From these observations may be determined the freezing point and the amount of impurity, the latter with a sensitivity as great as 0.00001 mole fraction (see, for example, [2,3]). With the same apparatus, measurements may be made of the apparent heat capacity of the "solid" at a number of temperatures below the freezing point, which will measure the amount of "premelting" at these temperatures. From these observations the amount of impurity may be calculated, with a sensitivity as great as 0.00001 mole fraction (see, for example, references $[4,5]$ ).

A new method for determining the amount of impurity in a given "pure" substance is that recently developed at this Bureau by Schwab and Wichers [6]. This is a differential time-temperature freezing method involving observations on the given substance followed by duplicate observations on the same material plus a known amount of impurity. This differential method minimizes the experimental sources of error inherent in the simple method of making timetemperature observations only on the given substance, is well suited to the precise determination of small amounts of impurity, and has been satisfactorily tested on preparations of benzoic acid having amounts of impurity as low as 0.00001 mole fraction. However, the differential method cannot be used in those cases where it is necessary to retain the material under investigation in its original state of purity. This is important for hydrocarbons of high purity, which are usually available only in very limited quantities.

\section{THEORETICAL PART}

\section{THERMODYNAMIC RELATION INVOLVED}

For the equilibrium between a liquid phase consisting of two or more components and a crystalline phase consisting of one of those components, the thermodynamic relation between the temperature of 
equilibrium and the composition of the liquid phase, in terms of that component (hereafter, for convenience, called the major component or solvent) present in the two phases, is [7, 8]

$$
\begin{aligned}
-\ln N_{1}=-\ln \left(1-N_{2}\right)=N_{2}\left(1+1 / 2 N_{2}+1 / 3 N_{2}^{2}+\ldots\right)= \\
\left(\Delta H_{f 0} / R T_{f 0}^{2}\right) \Delta T\left[1+\left(1 / T_{f 0}-1 / 2 \Delta C_{p} / \Delta H_{f 0}\right) \Delta T+\ldots\right],
\end{aligned}
$$

where $N_{1}$ is the mole fraction of the major component in the liquid phase, $N_{2}$ is $1-N_{1}$ or the sum of the mole fractions of all the other components in the liquid phase; $R$ is the gas constant; $T_{f 0}$ is the absolute temperature of the freezing point of the given substance when pure (that is, when $N_{1}=1$ or $N_{2}=0$ ); $\Delta H_{f 0}$ is the heat of fusion of the major component in the pure state at the temperature, $T_{f 0} ; \Delta C_{p}$ is, for the major component, the heat capacity of the liquid less that of the solid; and $\Delta T$ is $T_{f 0}-T$, where $T$ is the given temperature of equilibrium. In the derivation of eq 1 , the assumptions involved are the following: (1) the liquid solution is ideal, or sufficiently dilute that the fugacity of the solute is proportional to its mole fraction; (2) the heat of dilution is negligible over the range of concentration from $N_{1}=1$ to the given value of $N_{1}$; and (3) the value of $\Delta C_{p}$ is constant over the range of temperature $T$ to $T_{f 0}$. When the values of $\Delta H_{f 0}, T_{f 0}$, and $\Delta C_{p}$ are known, eq 1 permits evaluation of the mole fraction of liquid-soluble, solid-insoluble solute, $N_{2}$, from the value of the lowering of the freezing point, $\Delta T$, and conversely evaluation of $\Delta T$ from the value of $N_{2}$.

For the substances with which the authors are primarily concerned, namely, the paraffin, naphthene (cycloparaffin), and aromatic hydrocarbons occurring in the gasoline and kerosene fractions of petroleum, the value of the term

$$
1 / T_{f 0}-1 / 2 \Delta C_{p} / \Delta H_{f 0}
$$

in eq 1 is small, and for several typical hydrocarbons of these classes, has the following values:

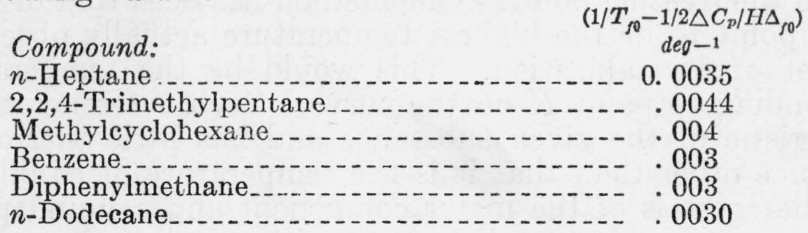

The order of magnitude of this term for such hydrocarbons is seen to be $0.004 / \mathrm{deg}$. Therefore, omission of the bracketed term on the right side of eq 1 will result in an error in the evaluation of $\mathrm{N}_{2}$ from values of $\Delta T$ (or of $\Delta T$ from values of $N_{2}$ ) equal to $(100)(0.004)(\Delta T)$ percent of the value of $N_{2}$ (or of $\Delta T$ ). That is to say, when $\Delta T$ has the values $0.1^{0}, 1^{0}$, and $5^{\circ}$, the errors caused by the omission of the bracketed term will be of the order of $0.04,0.4$ and 2 percent, respectively, of the value of $N_{2}$ or of $\Delta T$. Omission from eq 1 of the third and higher terms of the power series $\left(1 / 3 N_{2}^{2}+\ldots\right)$ on the left side will, for values of $N_{2}$ equal to $0.01,0.05,0.10$, and 0.25 mole fraction, result in errors of $0.003,0.08,0.3$, and 2 percent, respectively, of the value of $N_{2}$ or of $\Delta T$. 
It appears, therefore, that in calculating values of $N_{2}$ from values of $\Delta T$, or values of $\Delta T$ from values of $N_{2}$, when the amount of solute is less than one-fourth mole fraction and the value of $\Delta T$ is less than about $5^{\circ} \mathrm{C}$, there may be used the simplified relation ${ }^{4}$

$$
N_{2}\left(1+1 / 2 N_{2}\right)=\left(\Delta H_{f 0} / R T_{f 0}^{2}\right) \Delta T=A \Delta T,
$$

without introducing from this source errors greater than about 2 percent of the value of $N_{2}$ or of $\Delta T$, as the case may be.

\section{DETERMINATION OF THE FREEZING POINT}

In this paper, the freezing point of a given substance (solution) is taken to be that temperature at which crystals of the major component are in thermodynamic equilibrium with a liquid phase having the original composition of the given substance (solution). When, as is usually the case, the crystals of the major component are obtained from the solution itself, the freezing point is the temperature at which an infinitesimal amount of the crystalline phase of the major component is in thermodynamic equilibrium with the remainder of the substance in the liquid phase. The melting point of a given substance is thermodynamically identical with the freezing point as just defined.

No difficulty is normally experienced in determining, from timetemperature freezing curves, the value of the freezing point for a pure substance or for solutions (or impure substances) in which very little undercooling occurs. For substances containing significant amounts of impurity, or for solutions such as those used in determining molecular weights from the lowering of the freezing point, the occurrence of undercooling may produce significant errors if the freezing point is determined in the customary manner, even when thermodynamic equilibrium is established in the period immediately following the recovery from undercooling.

For such impure substances and solutions, undercooling produces a curve similar to that defined by the points $A B C D E F$ in figure 1 . In the interpretation of such a curve, two methods have been used to ascertain the freezing point. One method has been that of taking the freezing point to be the highest temperature actually observed after the onset of crystallization. This would be the temperature, $T_{K}$, corresponding to point $K$ on the curve. Such a temperature is not characteristic of the given substance and has little thermodynamic significance other than that it is the temperature of equilibrium between the crystals of the major component and a liquid phase containing a greater concentration of impurity or solute than the original substance contained, and that the freezing point of the substance or solution is higher than this temperature. The other and much more usual method is to extrapolate the portion $E F$ of the freezing curve back to its intersection at $B^{\prime \prime}$ with the line $A B C$. In a rigorous sense, this method also does not yield the proper value for the freezing point, and it will be shown in what follows that the freezing point is $T_{B^{\prime}}$ $\left(=T_{B}\right)$, a temperature slightly below $T_{B^{\prime \prime}}$.

In figure 1 , the curve $A B C D E F$ represents a real freezing curve with undercooling, and the curve $A^{\prime} B^{\prime} E F$ represents an ideal curve

\footnotetext{
${ }^{4}$ For convenience, the cryoscopic constant, $\triangle H_{f 0} / R T_{f 0}^{2}$, is hereafter designated by the symbol $A$. The most simplified form of eq 1 is of course

$\mathrm{N}_{2}=A \triangle T$.
} 
with no undercooling. In the latter case, $T_{B^{\prime}}$ (or $T_{B}$ ) is the true freezing point of the substance. When undercooling occurs, the substance and its container are for a time subjected to a smaller refrigerating head of temperature than would exist with no undercooling. The time required for a given amount of heat energy to be removed from the system during this period is therefore greater with undercooling than with no undercooling. If the ideal and real curves

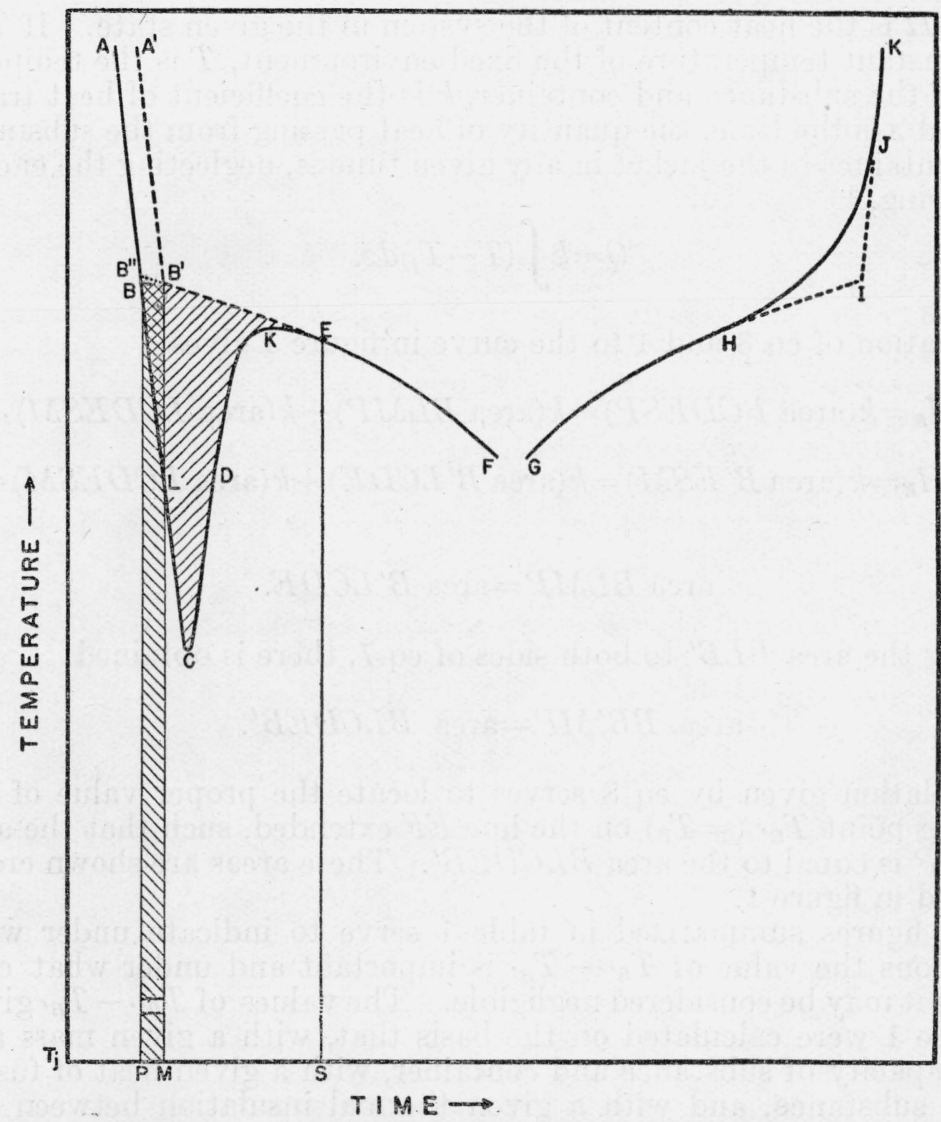

FIGURE 1.-Diagram of a time-temperature freezing curve with considerable undercooling, and of a melting curve, both for the same impure substance.

The scale of ordinates represents the temperature and the scale of abscissae the time. The diagram illustrates the method of determining the proper value of the freezing point and the initial time of freezing when undercooling occurs. See the text on p. 594-7 for explanation.

are made to coincide at $E$, then it follows that the time $z_{E}-z_{B}$ is greater than the time ${ }^{5} z_{E}-z_{B^{\prime}}$.

On the real curve $A B C D E F$ in figure 1, point $E$ represents the highest temperature at which thermodynamic equilibrium was established between the liquid and crystalline phases. With thermodynamic equilibrium existing in the given substance, the heat content of the substance and its container will be invariant at the temperature $T_{E}$,

$\checkmark$ When a constant head of temperature is used, instead of a constant jacket temperature as in the present discussion, it is apparent that $z_{B}-z_{B}$ is equal to $z_{B}-z_{B^{\prime}}$ and that $T_{B^{\prime}}$ and $T_{B^{\prime \prime}}$ coincide. 
and, likewise at the temperature $T_{B}\left(=T_{B^{\prime}}\right)$. Therefore, the decrease in heat content of the system as its temperature changes from $T_{B}$ to $T_{E}$ will be constant and independent of the path. So, for example, the decrease in heat content of the system as it passes from $T_{B}$ to $T_{E}$ along the path $B C D E$ will be the same as along the path $B^{\prime} E$. That is to say,

$$
H_{B}-H_{\boldsymbol{B}}=H_{B^{\prime}}-H_{E},
$$

where $H$ is the heat content of the system in the given state. If $T_{j}$ is the constant temperature of the fixed environment, $T$ is the temperature of the substance and container, $k$ is the coefficient of heat transfer, and $z$ is the time, the quantity of heat passing from the substance and container to the jacket in any given time is, negleeting the energy of stirring, ${ }^{6}$

$$
Q=k \int\left(T-T_{j}\right) d z .
$$

Application of eq 3 and 4 to the curve in figure 1 gives

$$
\begin{aligned}
& H_{B}-H_{L}=k(\text { area } B C D E S P)=k(\text { area } B L M P)+k(\text { area } L C D E S M), \\
& H_{B^{\prime}}-H_{E}=k\left(\text { area } B^{\prime} E S M\right)=k\left(\text { area } B^{\prime} L C D E\right)+k(\text { area } L C D E S M) .
\end{aligned}
$$

Hence

$$
\text { area } B L M P=\text { area } B^{\prime} L C D E \text {. }
$$

Adding the area $B L B^{\prime}$ to both sides of eq 7 , there is obtained

$$
\text { area } B B^{\prime} M P=\text { area } B L C D E B^{\prime} \text {. }
$$

The relation given by eq 8 serves to locate the proper value of the freezing point $T_{B^{\prime}}\left(=T_{B}\right)$ on the line $E F$ extended, such that the area $B B^{\prime} M P$ is equal to the area $B L C D E B^{\prime}$. These areas are shown crosshatched in figure 1.

The figures summarized in table 1 serve to indicate under what conditions the value of $T_{B^{\prime \prime}}-T_{B^{\prime}}$ is important and under what conditions it may be considered negligible. The values of $T_{B^{\prime \prime}}-T_{B^{\prime}}$ given in table 1 were calculated on the basis that, with a given mass and heat capacity of substance and container, with a given heat of fusion of the substance, and with a given thermal insulation between the container of the substance and the jacket, the following conditions hold: (a) the cooling rate is $0.02^{\circ} / \mathrm{min} \mathrm{deg}$; (b) the total time of freezing of the pure substance is 40 minutes when the head of temperature is $50^{\circ} \mathrm{C}$; (c) 0.01 mole fraction of solute produces a lowering of $0.3^{\circ} \mathrm{C}$ in the freezing point.

o To approach conditions of thermodynamic equilibrium it will be seen from section III-2 that stirring is required. In this case if $u$ is the heat evolved in unit time by stirring, the equations corresponding to 4 and 7 are, respectively,

$$
Q=k \int\left(T-T_{j}\right) \mathrm{d} z+u \int \mathrm{d} z
$$

and $k$ (area $B L M P)+u\left(z_{B^{\prime}}-z_{B}\right)=k\left(\right.$ area $\left.B^{\prime} L C D E\right)$.

With an apparatus of the kind described in section III, the stirring energy is usually only several percent of the heat energy transferred as a result of the thermal head and consequently the term $u\left(z_{B^{\prime}}-z_{B}\right)$ may be neglected in comparison with $k($ area $B L M P)$. 
TABLE 1.-Values of $T_{B^{\prime \prime}}-T_{B^{\prime}}$ calculated for various conditions ${ }^{a}$

\begin{tabular}{|c|c|c|c|c|c|c|c|}
\hline \multirow{2}{*}{ Case } & \multirow{2}{*}{$\begin{array}{c}\text { Time of } \\
\text { freezing a }\end{array}$} & \multirow{2}{*}{$\begin{array}{c}\text { Head of } \\
\text { tempera- } \\
\text { ture }\end{array}$} & \multirow{2}{*}{$\begin{array}{l}\text { Extent of } \\
\text { under- } \\
\text { cooling }\end{array}$} & \multirow{2}{*}{$\begin{array}{l}\text { Concen- } \\
\text { tration of } \\
\text { solute }\end{array}$} & \multirow{2}{*}{$\left(T_{f_{0}}-T_{f}\right) \mathrm{d}$} & \multicolumn{2}{|c|}{ Value of $T_{B^{\prime \prime}}-T_{B^{\prime}}$} \\
\hline & & & & & & I b & II 0 \\
\hline $\begin{array}{l}\text { la } \\
\text { lb..... } \\
\text { lc }\end{array}$ & $\begin{array}{r}\min \\
40 \\
40 \\
40\end{array}$ & $\begin{array}{r}{ }^{\circ} \mathrm{C} \\
50 \\
50 \\
50\end{array}$ & $\begin{array}{l}{ }^{\circ} \mathrm{C} \\
{ }^{\circ} \\
\\
\\
\\
\\
5 \\
5\end{array}$ & $\begin{array}{c}\text { mole fraction } \\
0.002 \\
.02 \\
.10\end{array}$ & $\begin{array}{c}{ }^{\circ} \mathrm{C} \\
0.06 \\
.6 \\
3.0\end{array}$ & $\begin{array}{l}{ }^{\circ} \mathrm{C} \\
0.0010 \\
.010 \\
.045\end{array}$ & $\begin{array}{c}{ }^{\circ} C \\
0.0014 \\
.014 \\
.065\end{array}$ \\
\hline $\begin{array}{l}2 \mathrm{a}-\ldots . \\
2 \mathrm{~b}-\ldots . \\
2 \mathrm{c}-\ldots .-\end{array}$ & $\begin{array}{l}40 \\
40 \\
40\end{array}$ & $\begin{array}{l}50 \\
50 \\
50\end{array}$ & $\begin{array}{r}1 \\
5 \\
10\end{array}$ & $\begin{array}{l}.02 \\
.02 \\
.02\end{array}$ & $\begin{array}{r}0.6 \\
.6 \\
.6\end{array}$ & $\begin{array}{l}.0006 \\
.010 \\
.036\end{array}$ & $\begin{array}{l}.0017 \\
.014\end{array}$ \\
\hline $\begin{array}{l}3 \mathrm{a}- \\
3 \mathrm{~b}-\ldots \\
3 \mathrm{c}-\ldots\end{array}$ & $\begin{array}{r}200 \\
40 \\
20\end{array}$ & $\begin{array}{r}10 \\
50 \\
100\end{array}$ & $\begin{array}{l}5 \\
5 \\
5\end{array}$ & $\begin{array}{l}.02 \\
.02 \\
.02\end{array}$ & $\begin{array}{l}.6 \\
.6 \\
.6\end{array}$ & $\begin{array}{l}.060 \\
.010 \\
.006\end{array}$ & $\begin{array}{l}.066 \\
.014 \\
.010\end{array}$ \\
\hline 4 & 200 & 10 & 5 & .10 & 3.0 & .27 & .29 \\
\hline
\end{tabular}

a See text for explanation.

b Calculated on the assumption of recovery from undercooling in $2 \mathrm{~min}$.

- Calculated on the assumption of recovery from undercooling in $5 \mathrm{~min}$

d Lowering of the freezing point caused by the given concentration of solute.

From the values given in table 1 , it is evident that, when the extent of undercooling is small in comparison with the head of temperature, the value of $T_{B^{\prime \prime}}-T_{B^{\prime}}$ is small and of the order of several percent of $T_{f_{0}}-T_{f}$, the lowering of the freezing point caused by the given concentration of solute (or impurity). However, when the amount of undercooling is large in comparison with the head of temperature, as in case 4 , the value of $T_{B^{\prime \prime}}-T_{B^{\prime}}$ becomes quite important.

This method of determining the proper value of the freezing point is of importance in evaluating molecular weights by that cryoscopic method wherein the freezing points are determined from time-temperature curves. Frequently in such experiments, the thermal head is small and considerable undercooling occurs, and the foregoing correction is quite significant.

The freezing point as defined here is a definite temperature of equilibrium between the liquid phase and an infinitesimal amount of the crystalline phase of the major component. This equilibrium point can be approached from the low-temperature side as well as from the high-temperature side, that is, from a melting curve as well as from a freezing curve. On the right-hand side of figure 1, the curve GHJK is a melting curve in which the portion $G H$ is assumed to represent thermodynamic equilibrium between the liquid and crystals of the major component. $H J$ is the portion during which the crystals and liquid still coexist but are no longer in thermodynamic equilibrium, and $J K$ represents the warming curve for the liquid. The freezing point, $T_{I}$, as obtained by extrapolation of $G H$ to its intersection with the extension of $K J$ at $I$, should be identical with the freezing point obtained by extrapolation of the freezing curve $F E$ to $T_{B^{\prime}}$, within the respective limits of uncertainty of the extrapolations, provided only that equilibrium does exist over the portions $G H$ and $F E$. Except for ideally pure substances the curves $B^{\prime} F$ and $I G$ are concave downward, and, if the rate of transfer of energy is the same in both cases (as assumed in figure 1), the curves will be mirror images of each other. 


\section{ESTIMATION OF THE AMOUNT OF IMPURITY}

In the estimation, from time-temperature freezing curves, of the amount of solid-insoluble, liquid-soluble impurity in a given substance by any procedure based on the method of White [1], the following assumptions are made:

(a) The impurity remains entirely in the liquid phase, at least until the end of the period for which the lowering of temperature is determined.

(b) For a given head of temperature between the substance and the cooling jacket, the rate of crystallization of the substance is constant.

(c) At the times between which the lowering of the temperature is measured, the system of liquid and crystals is in thermodynamic equilibrium.

(d) The liquid-soluble, solid-insoluble impurity forms with the given substance in the liquid phase an ideal solution or a nonideal solution sufficiently dilute that eq 1 (or a simplified form of it) may be applied.

Let $N_{2}^{*}$ be the mole fraction of impurity in the original substance, $z_{0}$ the time at which crystallization begins if no undercooling occurs (or, if undercooling occurs, the time at which crystallization would have begun in the absence of undercooling), $z_{f}$ the time at which crystallization of the substance (major component plus impurity) is substantially complete (corrected, if necessary, for any significant change in the head of temperature and for any change in stirring), and $r$ the fraction of the substance crystallized. Then, if the heat of fusion of the impurity is substantially the same as that of the major component, ${ }^{7}$ the mole fraction of solute in the liquid phase at any time $z$, is

$$
N_{2}=N_{2}^{*}\left(z_{f}-z_{0}\right) /\left(z_{f}-z\right)=N_{2}^{*} /(1-r) .
$$

If the temperatures at the times $z_{0}$ and $z$ are those of equilibrium between the liquid and crystalline phases and have the values $T_{z_{0}}$ and $T_{z}$, respectively, then the lowering of temperature, $T_{z_{0}}-T_{z}$, is produced by an increase in mole fraction of solute in the liquid phase equal to

$$
N_{2}-N_{2}^{*}=N_{2}^{*}\left(z-z_{0}\right) /\left(z_{f}-z\right)=N_{2}^{*} r /(1-r) .
$$

For the investigations carried on in this laboratory (and probably in most others), the simplified eq 2 may, with appropriate limitations on the values of $N_{2}$ and $T_{\gamma_{0}}-T_{z}$, be applied to determine the value of $N_{2}{ }^{*}$. The following relation holds for the time $z_{0}$ :

$$
N_{2}^{*}\left(1+1 / 2 N_{2}^{*}\right)=A\left(T_{f_{0}}-T_{z_{0}}\right) .
$$

Likewise, at the time $z$,

$$
N_{2}\left(1+1 / 2 N_{2}\right)=A\left(T_{f_{0}}-T_{z}\right) .
$$

Combination of eq 9,11 , and 12 , with the elimination of $T_{f_{0}}$ and $N_{2}$, yields the following relation for $N_{2}^{*}$, the wanted mole fraction of impurity in the original substance:

$$
N_{2}^{*}=\frac{1-r}{2-r}\left(-1+\sqrt{1+\left(\frac{2-r}{r}\right) 2 A\left(T_{z_{0}}-T_{z}\right)}\right)
$$

7 The effect of a difference in heat of fusion between the impurity and the major component is discussed in section III-4. 
For values of $r$ equal to $1 / 5,1 / 4$, and $1 / 3$, the corresponding equations for $N_{2}^{*}$ are as follows:

$$
\begin{aligned}
& \text { For } r=1 / 5: N_{2}^{*}=\frac{4}{9}\left(-1+\sqrt{1+18 A\left(T_{z_{0}}-T_{z}\right)}\right) \\
& \text { For } r=1 / 4: N_{2}^{*}=\frac{3}{7}\left(-1+\sqrt{1+14 A\left(T_{z_{0}}-T_{z}\right)}\right) . \\
& \text { For } r=1 / 3: N_{2}^{*}=\frac{2}{5}\left(-1+\sqrt{1+10 A\left(T_{z_{0}}-T_{z}\right.}\right)
\end{aligned}
$$

If, for any given case, the value of $1 / 2 N_{2}$ is small enough in comparison with unity to be neglected, then combination of eq 9,11 , and 12 yields for $N_{2}^{*}$ the simple relation

$$
N_{2}^{*}=\frac{1-r}{r} A\left(T_{z_{0}}-T_{z}\right)
$$

For values of $r$ equal to $1 / 5,1 / 4$, and $1 / 3$, the values of the coefficient $(1-r) / r$ are 4,3 , and 2 , respectively.

When values of $N_{2}^{*}$ and $T_{z_{0}}$ are known, the value of $T_{f_{0}}$, the freezing point of the given substance when it contains no impurity, may be calculated from eq 11.

In order to evaluate $N_{2}^{*}$, it is necessary to determine the times $z_{0}, z$, and $z_{f}$ and the temperatures $T_{z_{0}}$ and $T_{z}$ corresponding to $z_{0}$ and $z$. The three times must be corrected, if necessary, to a constant head of temperature, and, if necessary, for any significant change in the rate of introduction of energy by stirring; and the two temperatures must be determined from that portion of the freezing curve that corresponds to thermodynamic equilibrium between the liquid and crystalline phases.

The determination of the value of $T_{z_{0}}$, which is $T_{f}$, has already been discussed in the preceding part of this section.

The time $z_{0}$ is the time at which crystallization would have begun if no undercooling occurred, and, in figure 1 , is the time at which the curve EF (representing equilibrium) extrapolates to the proper value, $T_{B}{ }^{\prime}$, of the freezing point of the given substance.

There is next to be determined the proper final time of crystallization. The curve ABCDEFGH in figure 2 represents a time-temperature curve for a substance containing several mole percent of impurity made up of several components. In this example, the substance has all just crystallized at the temperature $T_{G}$. It will be noted that, contrary to the simple type of curve obtained with nearly pure substances, there is no sharp break to mark the time when all of the substance has crystallized. Since the head of temperature, and consequently the rate of transfer of heat, is continually decreasing, the cooling curve for the solid phase is concave upward, as from $G$ to $H$, and approaches the temperature of the jacket asymptotically, the rate of change at any time being proportional to the head of temperature.

The curve $A^{\prime} B^{\prime} E F G H$ represents the time-temperature curve for the same substance under similar conditions, but in the absence of undercooling. The curve $A^{\prime} B^{\prime} I^{\prime} G^{\prime} H^{\prime}$ represents a hypothetical process for the same system under similar conditions in which the crys- 
tallization occurs at a constant head of temperature along the line $B^{\prime} I^{\prime}$, and then the solid phase is cooled along the line $I^{\prime} G^{\prime} H^{\prime}$. There is required to be determined the time at $I^{\prime}$ at which all of the substance would have been crystallized had the head of temperature remained at the value $T_{B^{\prime}}-T_{j}$ which it had at the beginning of crystallization at $B^{\prime}$. In the actual process with no undercooling, as along the path $A^{\prime} B^{\prime} E F G H$, the substance has become all solid at the time $G$. Now

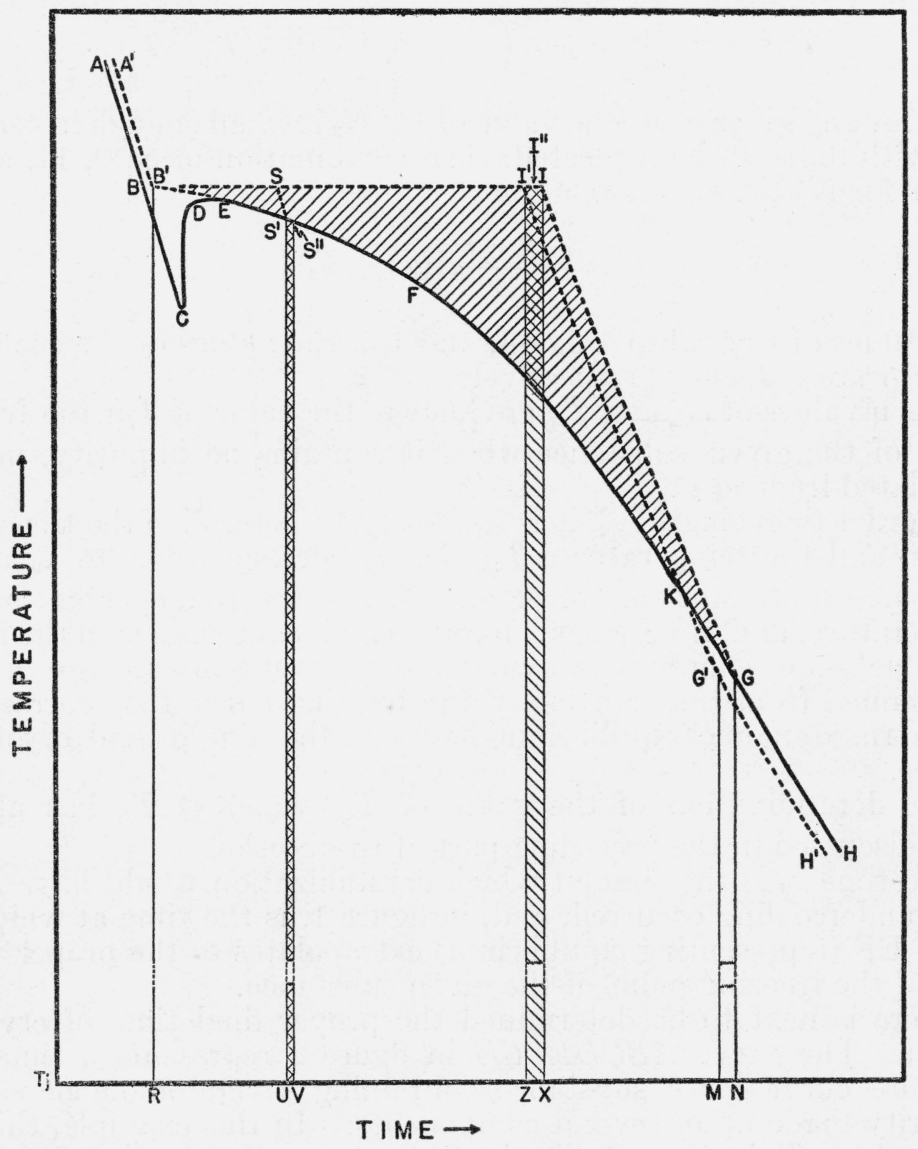

FIgURE 2.-Schematic diagram of a time-temperature freezing curve.

The scale of ordinates represents the temperature and the scale of abscissae the time. The diagram, which illustrates steps in the determination of the final time of freezing and of the equilibrium temperature at a selected time, is explained in the text on p. 599-601.

the time from $B^{\prime}$ to $G$ is longer than the required time from $B^{\prime}$ to $I^{\prime}$ by the following two amounts: (a) the time from $I^{\prime}$ to $G^{\prime}$, which is the time required to cool the solid phase from the temperature $T_{I^{\prime}}$ to the temperature $T_{G^{\prime}} ;$ and (b) the time from $I^{\prime}$ to $I$, which accounts for the lower average head of temperature existing along the path $A^{\prime} B^{\prime} E F G H$ as compared with the path $A^{\prime} B^{\prime} I^{\prime} G^{\prime} H^{\prime}$.

The point $I^{\prime}$ is located as follows: The curved line $G H$ is extrapolated back to its intersection with a horizontal line through $B^{\prime}$ to locate the point $I$. This extrapolation can be made from the time- 
temperature plot only if the distance from $G$ to $I$ is small, as in the case of a nearly pure substance with a large head of temperature, when the line will appear substantially straight. In most cases, however, it is necessary to plot the logarithm of the head of temperature against the time, as in figure 3 , in which case the line $G H$ is linear and can be readily extrapolated back to locate the point $I$. The points $G$ and $I$ are then located in figure 2 from their values of time and temperature as determined in figure 3. The point $I^{\prime}$ is then located on the line $B^{\prime} I$ by making the area $K G N M G^{\prime}$ equal to the area $B^{\prime} I^{\prime} K F E$ or, what is equivalent and simpler, the area $I^{\prime} I X Z$ equal to the area $B^{\prime} I G F E$. The lines $I^{\prime} G^{\prime} H^{\prime}$ and $I G H$ are parallel and represent the same process in the same length of time but occurring at different times. That this is the proper location of the point $I^{\prime}$, may be proved by the same argument as on page 596. Since $T_{G^{\prime}}$

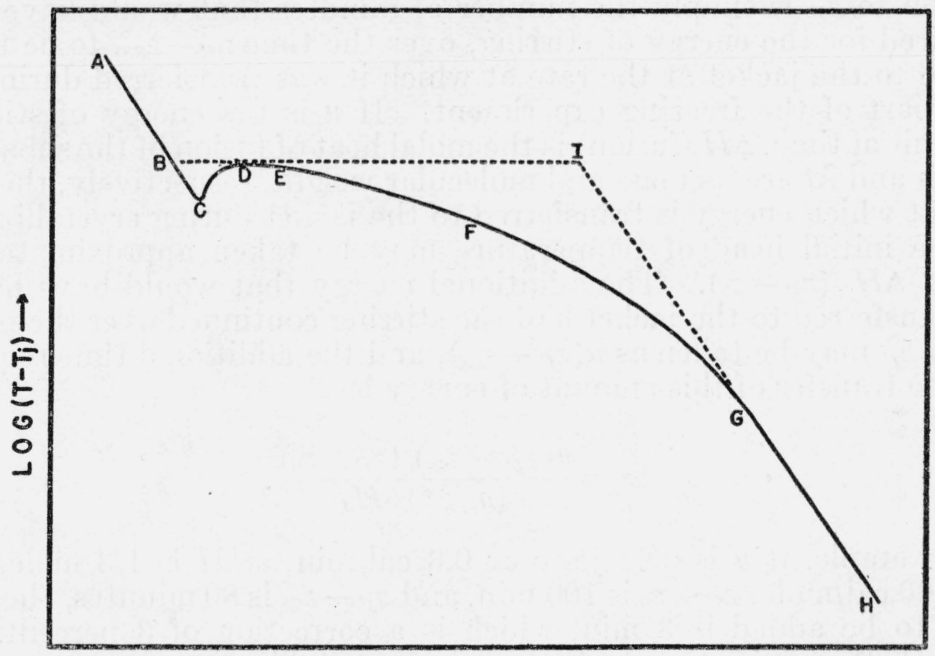

FIGURE 3.-Diagram showing the method of plotting a freezing curve to determine the total time of freezing.

The scale of ordinates represents the logarithm of the head of temperature, $\log \left(T-T_{i}\right)$, and the scale of abscissae represents the time. See the text on p. 601 for explanation.

and $T_{G}$ are equal and the system is the same in the two cases, then the change in heat content along the path $B^{\prime} E F G$ is the same as along the path $B^{\prime} I^{\prime} G^{\prime}$. Therefore,

and hence

$$
k\left(\text { area } B^{\prime} I^{\prime} G^{\prime} M R\right)=k\left(\text { area } B^{\prime} E F G N R\right)
$$

$$
\text { area } B^{\prime} E F K I^{\prime}=\text { area } K G N M G^{\prime} \text {. }
$$

It can also be shown, by proceeding along the path $B^{\prime} E F G$ and then along the path $B^{\prime} I^{\prime} Z X I G$, that

$$
\text { area } I^{\prime} I X Z=\text { area } B^{\prime} I G F E \text {. }
$$

In actual practice, the point $I^{\prime}$ is located directly by making the area $I^{\prime} I X Z$ equal to the area $B^{\prime} I G F E$. The time at $I^{\prime}$ is taken as the value of $z_{f^{\prime}}$. In determining $z_{f^{\prime}}$, the following points may be noted: (a) When the head of temperature is large, $\left(T_{B^{\prime}}-T_{j}\right)$, or $I X$, will be large, 
and to balance a given area $B^{\prime} I G F E, I^{\prime} I$ may be small; (b) when the substance is relatively pure (containing about 0.01 mole fraction or less of solute), the area $B^{\prime} I G F E$ will be small, and the points $I^{\prime}$ and $I$ will be nearly identical.

In the case of relatively pure substances and with a large head of temperature, a time-temperature curve will be obtained in which a simple extrapolation of the final slope to its intersection at the value of $T_{z 0}$ will suffice to determine the value of $z_{f^{\prime}}$ within the significance of the present investigation.

The value of $z_{f^{\prime}}$ determined in the manner just outlined is subject to one further correction, resulting from the fact that the energy of stirring was not contributed to the system during all the time $z_{f^{\prime}}-z_{0}$, but only during the first part of that time (see section III-3). This correction is made as follows:

Let $z_{S S}$ be the time at which the stirrer is stopped. Then the correction to $z_{f}$ is simply the number of minutes that would have been required for the energy of stirring, over the time $z_{f^{\prime}}-z_{\mathrm{SS}}$, to be transferred to the jacket at the rate at which it was transferred during the first part of the freezing experiment. If $u$ is the energy of stirring, per unit of time, $\Delta H$ (fusion) is the molal heat of fusion of the substance and $m$ and $M$ are its mass and molecular weight, respectively, then the rate at which energy is transferred to the jacket during crystallization at the initial head of temperature may be taken approximately as $(m / M) \Delta H_{f} /\left(z_{f^{\prime}}-z_{0}\right)$. The additional energy that would have had to be transferred to the jacket had the stirring continued over the period $z_{S S}$ to $z_{f^{\prime}}$ may be taken as $u\left(z_{f^{\prime}}-z_{S S}\right)$, and the additional time required for the transfer of this amount of energy is

$$
\Delta z_{f}=\frac{u\left(z_{f^{\prime}}-z_{S S}\right)\left(z_{f^{\prime}}-z_{0}\right)}{(m / M) \Delta H_{f}} .
$$

For example, if $u$ is $0.02 \mathrm{j} / \mathrm{sec}$ or $0.3 \mathrm{cal} / \mathrm{min}, \mathrm{m} / M$ is $1 / 3 \mathrm{~mole}, \Delta H_{\text {g }}$ is $2,400 \mathrm{cal} / \mathrm{mole}, z_{f^{\prime}}-z_{0}$ is $100 \mathrm{~min}$, and $z_{f^{\prime}}-z_{S S}$ is 80 minutes, then the time to be added is $3 \mathrm{~min}$, which is a correction of 3 percent. In general, this correction to the time of crystallization, because of the lack of stirring in the latter part of the experiment, will be significant when the time over which the stirrer is not in operation is large, when the stirring energy per unit of time is large, and when the total heat of fusion of the substance is small. The accuracy of this correction will depend largely upon the constancy of the energy of stirring, which will be discussed in section III-4.

In figure 2 on the line $B^{\prime} I^{\prime}$ extended, there is located the point $I^{\prime \prime}$ so that the time from $I^{\prime}$ to $I^{\prime \prime}$ is equal to $\Delta z_{f}$ or $z_{f^{\prime}}-z_{f}$, as given by eq 21. This point $I^{\prime \prime}$ corresponds to the final time corrected to the head of temperature $T_{z_{0}}-T_{j}$ and corrected for stirring. There now remains to be determined $T_{z}$, the temperature at the time $z$. The time $z$ should be taken as large as possible without going beyond the time at which equilibrium exists between the liquid and crystalline phases (see point $F$ in fig. 5). Referring to figure 2, there is first located the point $S$ on the line $B^{\prime} I^{\prime \prime}$ so that $B^{\prime} S$ is a known fraction of $B^{\prime} I^{\prime \prime}$. From $S$ a line is drawn parallel to $A B$, intersecting $E F$ at $S^{\prime}$. The value of $T_{z}$ corresponding to the selected time $z$ is that at a point $S^{\prime \prime}$ located on the curve $E F$ at a point slightly below $S^{\prime}$ so that the area $B^{\prime} S S^{\prime}$ is equal to the area $S^{\prime \prime} S^{\prime} U V$. Except in the case of very impure sub- 
stances, or, in those cases where the head of temperature is relatively small, the area $B^{\prime} S S^{\prime}$ will be small and $S^{\prime \prime}$ will not differ significantly from $S^{\prime}$. The effect of stirring on the relation between $S^{\prime}$ and $S^{\prime \prime}$ is the same as that discussed in section II-2 on the relation between $B$ and $B^{\prime}$ in figure 1 .

It should be noted that in the foregoing procedure there is little uncertainty in determining the values of $z_{0}$ and $T_{z_{0}}$. Likewise, there is little uncertainty in determining the value of $T_{z}$ corresponding to a given $z$, once the value of $z_{f}$ is fixed. Therefore, practically all of the uncertainty in the estimation of the amount of impurity by this method lies in the determination of the proper value of $z_{f}$, defined as the time at which the substance would have been substantially all crystallized had the rate of crystallization remained constant; that is, at its value at the beginning of the freezing period.

In addition to those factors whose effect upon the rate (and hence the total time) of crystallization have been evaluated quantitatively, there exist other factors which are not amenable to such evaluation and which may contribute important uncertainties in the determination of the total time, $z_{f}-z_{0}$, as just outlined. Since all except one of these factors may be varied in magnitude by appropriate change in the experimental apparatus and procedure, they are discussed in section III-4.

In case the substance is one for which the heat of fusion is not known, an estimate of it may be made by a comparison with observations on a substance whose heat of fusion is known. The procedure is as follows (see also [18]): Select a similar substance $A$, whose heat of fusion is known and whose freezing point is within about $20^{\circ} \mathrm{C}$ of that of the substance $B$, whose heat of fusion is to be estimated. Let $m_{A}, M_{A}$, and $\left(\Delta H_{f}\right)_{A}$ be the mass, molecular weight, and heat of fusion of the substance $A$, and, likewise, $m_{B}, M_{B}$, and $\left(\Delta H_{f}\right)_{B}$ those for the substance $B$. Perform a complete time-temperature freezing experiment on the substance $A$, and likewise on the substance $B$, using the same volume of substance in each case and the same jacket temperature, $T_{j}$. From the time-temperature curve for $A$, determine $\left(z_{f}-z_{0}\right)_{A}$, the corrected total time of freezing, and likewise $\left(z_{f}-z_{0}\right)_{B}$ from the curve for $B$. From these two experiments, the heat of fusion of the unknown substance $B$ may be calculated in two different ways.

One method utilizes the value of the head of temperature for each experiment together with the assumption that the coefficient of heat transfer, $k$, is the same in the two experiments. Then

$$
(m / M)_{A}\left(\Delta H_{f}\right)_{A}=k\left(z_{f}-z_{0}\right)_{A}\left(T_{z_{0}}-T_{j}\right)_{A},
$$

and

$$
(m / M)_{B}\left(\Delta H_{f}\right)_{B}=k\left(z_{f}-z_{0}\right)_{B}\left(T_{z_{0}}-T_{j}\right)_{B} .
$$

On eliminating $k$ there is obtained

$$
\left(\Delta H_{f}\right)_{B}=\left(\Delta H_{f}\right)_{A} \frac{(m / M)_{A}\left(z_{f}-z_{0}\right)_{B}\left(T_{z_{0}}-T_{j}\right)_{B}}{(m / M)_{B}\left(z_{f}-z_{0}\right)_{A}\left(T_{z_{0}}-T_{j}\right)_{A}} .
$$


The heat transfer coefficient will be constant within the required limits if the evacuated space of the freezing tube has been sealed off, the jacket temperature is made the same for both $A$ and $B$, and the two experiments are performed at not greatly different times.

The other method utilizes for each experiment the value of the effective heat capacity of the system, including $C$, that of the hydrocarbon, and $c$, that of the thermometer, stirrer, and container, together with the value of $(d T / d z)^{*}$, the rate of change of temperature with time at the temperature $T_{z_{0}}$ just before crystallization begins. The value of $(d T / d z)^{*}$ is determined from the freezing curve obtained on the "unknown," $B$. The value of $c$, the effective heat capacity of the container, etc., is determined from complete time-temperature freezing curves obtained for substances having known heats of fusion and known heat capacities in the liquid state near the freezing point, and having freezing points higher and lower than those of the "unknowns" to be investigated. The relation employed to evaluate $c$ at the desired temperatures is

$$
c=\frac{(m / M)_{A}\left(\Delta H_{f}\right)_{A}}{\left(z_{f}-z_{0}\right)_{A}(d T / d z)_{A}^{*}}-C_{A} \cdot
$$

The heat of fusion of the "unknown" $B$ is given by the relation

$$
\left(\Delta H_{f}\right)_{B}=\frac{\left(c+C_{B}\right)(d T / d z)_{B}^{*}\left(z_{f}-z_{0}\right)_{B}}{(m / M)_{B}}
$$

The heat capacity of the hydrocarbon $B$ in the liquid state at the given temperature may, if not known, be assumed equal to the heat capacity of that mass of a hydrocarbon of similar size and type having the same volume at room temperature. In an apparatus of the kind described in section III-1, the hydrocarbon (50 ml at room temperature) contributes about 80 percent of the effective heat capacity of the system. Examination of the available data indicates that for the hydrocarbons, $n$-hexane, $n$-heptane, 2 -methylhexane, 2,2,4-trimethylpentane, methylcyclopentane, cyclohexene, methylcyclohexane, 1,2-dimethylcyclopentane, and 1,2,4-trimethylbenzene, those masses of hydrocarbon which are contained in a volume of $50 \mathrm{ml}$ at $20^{\circ} \mathrm{C}$ will have, in the liquid state, heat capacities ranging as follows: at $0^{\circ} \mathrm{C}$, 15.8 to $18.0 \mathrm{cal} / \mathrm{deg}$; at $-50^{\circ} \mathrm{C}, 14.3$ to $16.7 \mathrm{cal} / \mathrm{deg}$; at $-75^{\circ} \mathrm{C}, 13.9$ to $16.5 \mathrm{cal} / \mathrm{deg}$. The variation between compounds of the same size and type is smaller than this.

If the heat of fusion is known for the substance, $B$, whose amount of impurity is to be determined, and if the coefficient of heat transfer is known for the given jacket conditions, the amount of impurity may be calculated entirely from the first part of the freezing curve for the substance $B$. The rate at which heat is being removed from the substance during crystallization at the temperature $T$ is $k\left(T-T_{j}\right)$, and, therefore, the time during which any given fraction, $r$, of the substance will have crystallized is

$$
z-z_{0}=\frac{r(m / M)_{B}\left(\Delta H_{f}\right)_{B}}{k\left(T-T_{j}\right)_{B}}
$$


The lowering of the equilibrium temperature from the time $z_{0}$ to the time $z$ gives the value of $T_{z_{0}}-T_{z}$ corresponding to the given value of $r$, from which the amount of impurity may be calculated using eq 13 or 17.

Likewise, if the heat of fusion is known for the substance whose amount of impurity is to be determined, and if the effective heat capacity of the container, etc., is known for the given temperature, the amount of impurity may be calculated entirely from the first part of the freezing curve for the given substance. In this case, the rate at which heat is being removed from the substance during crystallization at $T_{z_{0}}$ is $\left(c+C_{B}\right)(d T / d z)_{B}^{*}$, and, therefore, the time during which any given fraction, $r$, of the substance will have crystallized is

$$
z-z_{0}=\frac{r(m / M)_{B}\left(\Delta H_{f}\right)_{B}}{\left(c+C_{B}\right)(d T / d z)_{B}^{*}}
$$

As before, the lowering of the equilibrium temperature from the time $z_{0}$ to the time $z$ gives the value of $T_{z_{0}}-T_{z}$ corresponding to the given value of $r$, from which the amount of impurity may be calculated using eq 13 or 17.

The foregoing methods of estimating the amount of impurity from a partial time-temperature curve ${ }^{8}$ may be particularly useful in the case of substances (such as the methylcyclohexane described in connection with fig. 8) for which no part of the freezing curve represents thermodynamic equilibrium between liquid and solid. In such cases, the melting curve may be utilized, operating just as with a freezing curve except the reverse in point of time. The value of $k$ must be evaluated for the given jacket conditions, and the value of $(d T / d z)^{*}$ must be evaluated for the head of temperature corresponding to $T_{j}-T_{z_{0}}$.

\section{EXPERIMENTAL PART}

\section{APPARATUS}

A simple form of apparatus for obtaining time-temperature freezing and melting curves of the kind discussed in this report is shown in figure 4. This is substantially the same apparatus previously described by one of the authors (B. J. M. [9]). In figure 4, $A$ is the evacuated double-walled flask containing the substance under investigation; $B$ is a larger Dewar flask containing the liquid providing the constant temperature cooling or warming jacket; $C$ is the platinum resistance thermometer (Leeds \& Northrup No. 8163); $D$ is the stirrer, made of No. 15 AWG Nichrome wire and operated with a reciprocating stroke $5 \mathrm{~cm}$ long at a frequency of 85 to 120 strokes per minute; $E$ is a cork stopper. Tube $A$ has an inside diameter of $2.5 \mathrm{~cm}$ and a length of $29 \mathrm{~cm}$, and is normally filled to a depth of about $11 \mathrm{~cm} . \quad F$ is a thin, metal protecting tube.

With a stirrer which fits the containing tube closely, the accumulation of solid on the walls soon causes labored stirring. For this reason, a clearance of 1 to $2 \mathrm{~mm}$ is provided between the stirrer, $D$, and the inner walls of tube $A$. In the case of most hydrocarbons, it is possible to stir the substance until the time at which it is from one-fourth to one-third crystallized, with the longer times usually occurring with the more impure samples.

The authors acknowledge the benefits of discussion of these points with C. S. Cragoe of this Bureau. 




FIgURE 4.-Schematic diagram of the apparatus used in obtaining time-temperature freezing and melting curves.

See the text on p. 605 for explanation.
For substances $h$ a $v$ i $n g$. freezing points below room temperature, the most readily available materials for controlling the temperature of the jacket are ice, solid carbon dioxide, and liquid air. After the refrigerant suitable for the experiment in question has been selected, the thermal conductivity is adjusted to the desired value, as previously described [9], by changing the degree of evacuation of the double-walled tube. This tube, which is silvered to reduce heat transfer by radiation, is connected to a highvacuum oil pump through a ground-glass joint, in place of the usual rubber connection. In this way, a sufficiently low pressure is obtainable within a few minutes with a good pump.

The resistance of the platinum thermometer is measured on a Mueller resistance bridge (Leeds \& Northrup No. 8067) with a sensitivity on the galvanometer scale of $1.7 \mathrm{~mm}$ per $0.001^{\circ} \mathrm{C}$.

With $50 \mathrm{ml}$ of the hydrocarbon in the apparatus at about $-80^{\circ} \mathrm{C}$, the effective heat capacity of the substance and container, including appropriate portions of the thermometer and stirrer, is about $90 \mathrm{j} / \mathrm{deg}$, of which about 70 percent is due to the hydrocarbon. ${ }^{9}$ With the same amount of the same hydrocarbon at $-80^{\circ} \mathrm{C}$, the energy of stirring at the rate of 85 strokes per minute was determined to be $0.020 \pm 0.006$ $\mathrm{j} /$ sec. $^{10}$ Except for small rates

\footnotetext{
${ }_{9}$ The calculation was actually made for 2,2,4-trimethylpentane, but the result will be roughly the same for the same volume of any liquid hydrocarbon at this temperature [16].

10 The energy of stirring was determined by having the substance and container at about the temperature of the jacket, taking observations of temperature, with stirring, for a period of 12 to 15 min, stopping the stirrer for a known time of 3 to 5 min, again taking observations of temperature, with stirring, for another period of 12 to 15 minutes, etc. The cessation of stirring in a given period produces, between the two periods adjacent to it, an offset (decrease) of the time-temperature curve with respect to the temperature. Multiplication of this lowering of temperature by the heat capacity of the system gives the energy of stirring for the given period.
} 
of transfer of heat energy to the cooling jacket, stirring energy of this magnitude may be considered almost negligible. With $50 \mathrm{ml}$ of the hydrocarbon, 2,2,4-trimethylpentane, in the apparatus at about $-108^{\circ} \mathrm{C}$ and with a jacket temperature of $-185^{\circ} \mathrm{C}$ and a consequent head of temperature of $77^{\circ} \mathrm{C}$, the rate of transfer of heat energy to the jacket was calculated to be $1.2 \pm 0.2 \mathrm{j} / \mathrm{sec}$, when the Dewar fiask was evacuated to a point that gave a lowering of $0.8^{\circ} \mathrm{C} / \mathrm{min}$ for this system at this head of temperature. In this example, the stirring energy is nearly 2 percent of the total energy being transferred, and may be significant in connection with the determination of the total time of freezing (see section II-3).

\section{ATTAINMENT OF EQUILIBRIUM}

In order for the measurement of the temperature in a system of liquid and crystals to have thermodynamic significance, it is important to know that the system is in the state of thermodynamic equilibrium corresponding to that temperature. In figure 5 are shown three timetemperature curves obtained on a solution of 2,2,4-trimethylpentane containing 0.0266 mole fraction of solute (methylcyclohexane), using liquid air (temperature about $-185^{\circ} \mathrm{C}$ ), in the cooling jacket for the freezing curves and solid carbon dioxide (temperature about $-80^{\circ} \mathrm{C}$ ) for the melting curve. The time-temperature freezing curve shown in the upper left of the figure was obtained with the stirrer in operation up to the time designated by $S S$, while the stirrer was in operation throughout the determination of the melting curve shown in the upper right of the figure. However, in obtaining the freezing curve shown in the lower left of the figure, stirring was stopped at the time (designated by $S S$ ) shortly before complete recovery from undercooling: It was pointed out in section II-2 that extrapolation of the freezing and melting curves should lead to identical values for the freezing point within their respective limits of uncertainty, provided that equilibrium exists over the portions of the curve used in the extrapolation. Since extrapolations of the portions $F E$ and $K L$ (obtained with stirring) of the upper freezing and melting curves do give substantially the same value for the freezing point ( -108.015 and $-108.010^{\circ} \mathrm{C}$ ), it seems reasonable to conclude that over the portions $F E$ and $K L$ equilibrium was established (or a uniform departure from equilibrium occurred in both the freezing and melting experiments in such a way as to make them yield the same value for the freezing point on extrapolation). Extrapolation of the lower freezing curve, in which stirring was stopped before complete recovery from undercooling, yields the value $-108.136^{\circ} \mathrm{C}$, which is more than $0.1^{\circ} \mathrm{C}$ too low, and shows that equilibrium was not established over the portion of the curve used in this extrapolation.

Adequate stirring is necessary to establish and maintain equilibrium. This is also evident from the upper freezing curve, where there is a marked inflection at the point, $F$, at which time the stirrer stopped. In the period $F G$, during which the stirrer is no longer in operation, the temperature as recorded does not correspond to equilibrium for the given system of liquid and crystals. This change in slope at or preceding the cessation of stirring is characteristic of these curves and has been reported previously [9]. 


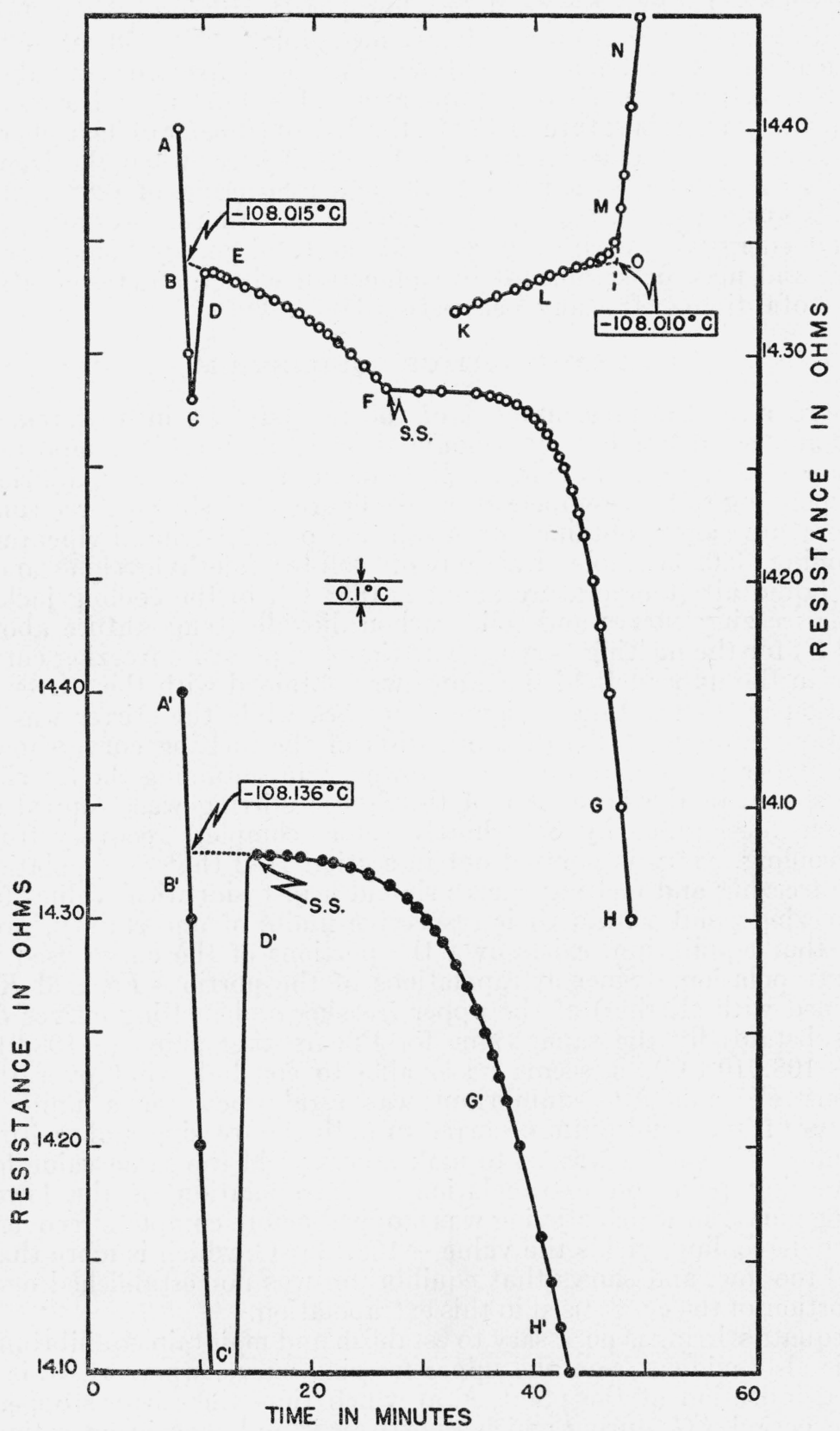

FIgURE 5.-Time-temperature freezing curves, with and without stirring, and a melting curve, with stirring, all taken on the same solution.

The scale of ordinates gives the resistance in ohms of the platinum-resistance thermometer $(0.1$ ohm $\approx$ $1^{\circ} \mathrm{C}$ ) and the scale of abscissae gives the time in minutes. The solution consisted of 2,2,4-trimethylpentane with 0.0266 mole fraction of solute (methylcyclohexane). See the text on p. 607 for explanation. 
Additional evidence that such a system is substantially in thermodynamic equilibrium over the portions of the curve indicated is provided in tables 3 and 4 . In table 3 , accord is shown between the experimentally determined freezing points and the values of the freezing points calculated from the known values of the mole fraction of solute, which indicates that at least the system was in substantial equilibrium near the freezing point. In table 4 is recorded the agreement between the known mole fraction of impurity and that evaluated from the lowering along the freezing curve. This establishes that the temperatures along the freezing curves, in the absence of compensating errors, were substantially equilibrium temperatures within the significance indicated.

There are some substances whose crystallization behavior is such that approach to thermodynamic equilibrium is not normally attained in the freezing experiment with stirring. A case of this kind is discussed on p. 612 .

\section{DETERMINATION OF THE FREEZING POINT}

As mentioned previously, extrapolation of the equilibrium portions of the freezing and melting curves should lead to identical values for the freezing point of a substance within the respective limits of uncertainty of the extrapolation. It is advisable, therefore, to check the reliability of the freezing point both from the freezing and melting curves. In general, the reliability of the value depends upon the extent of the extrapolation involved, the reliability increasing markedly with decrease in the extent of the extrapolation. Usually, as may be seen from figures 6 and 7 , which are self-explanatory, the freezing curve yields the more reliable value of the freezing point for the less concentrated solutions, whereas the melting curve yields the more reliable value for the more concentrated solutions. In any case, the two values of the freezing point determined from the freezing and melting curves should be in accord within the limits of uncertainty associated with the extrapolation of the respective curves, and a "best" value may be obtained by appropriate weighting of these two values.

As pointed out previously, in the case of substances having a significant amount of impurity, both the freezing and melting curves should be concave downward, and, if the rate of transfer of energy is the same in both cases, they should be mirror images of each other. If, then, a melting curve is obtained which has no portion concave downward, it is certain that equilibrium has not been attained. In such cases, the experiment should be repeated, with the system containing more of the crystalline phase before melting begins, or with a smaller rate of heat transfer, or preferably both, in order to obtain a sufficient portion of the melting curve in equilibrium (that is, concave downward) to permit reasonably reliable extrapolation of it to the liquid line. In the extrapolation of melting curves, one must guard against the tendency to consider as equilibrium measurements some of the points immediately following the point of inflection, ${ }^{11}$ which separates the part of the curve that is concave downward (equilibrium) from the part concave upward (nonequilibrium), and consequently

11 This point of inflection in the melting curve can be located easily by plotting with the time scale com. pressed much more than usual.

$315285-41-10$ 
to obtain, on extrapolation of the melting curve, a value of the freezing point higher than the proper one. With these precautions, timetemperature freezing and melting curves obtained with the apparatus

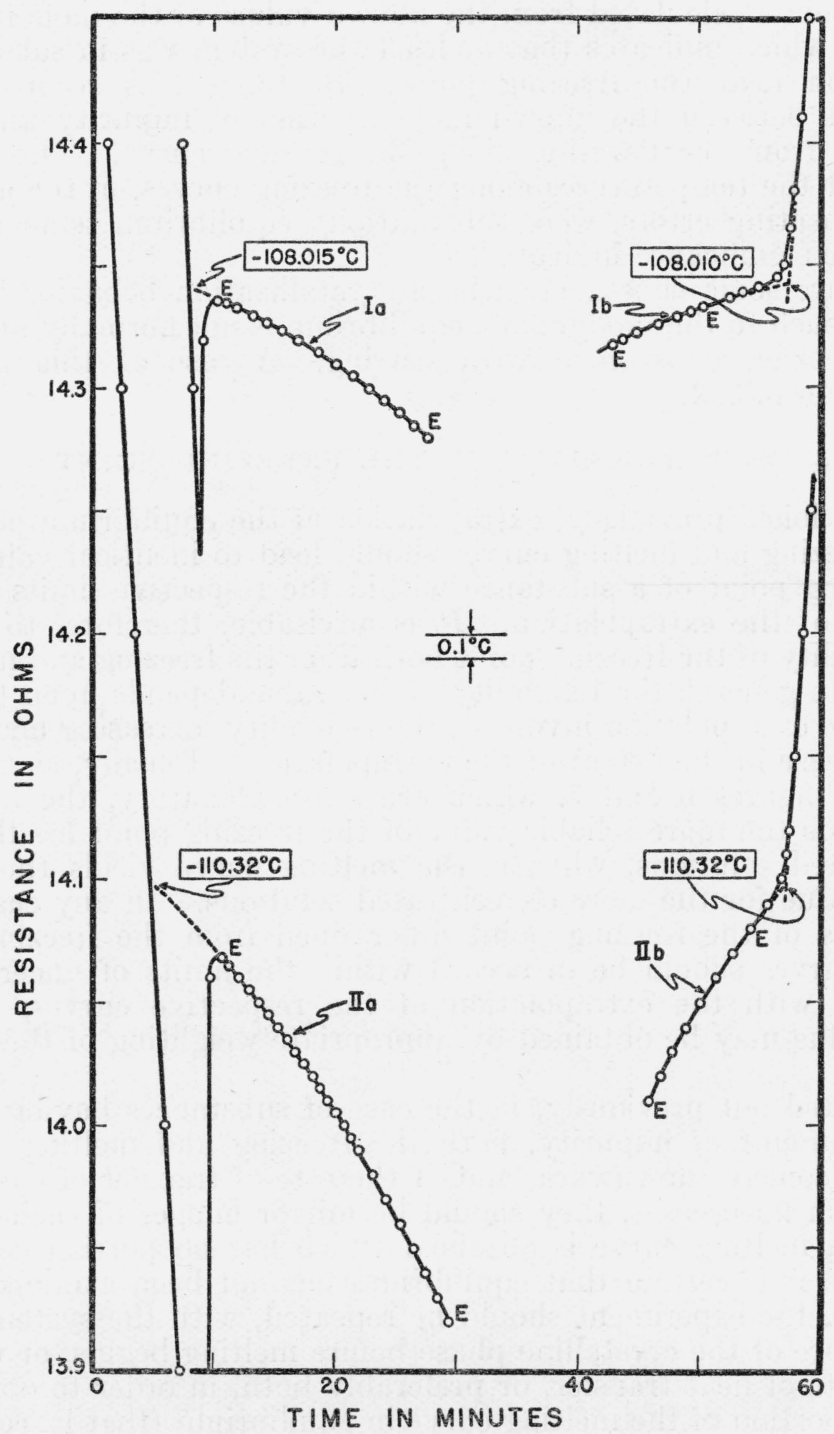

FIGURE 6.-Time-temperature freezing and melting curves for two different concentrations of the same solution.

The scale of ordinates gives the resistance in ohms of the platinum resistance thermometer $(0.1 \mathrm{ohm} \approx$ $\left.1^{\circ} \mathrm{C}\right)$, and the scale of abscissae gives the time in minutes. The upper curves were obtained on a solution of 2,2,4-trimethylpentane containing 0.0266 mole fraction of solute (methylcyclohexane) and the lower curves on the same system with the mole fraction of solute equal to 0.1147 .

and procedure described in this paper, and with substances that crystallize normally, will yield values of the freezing point that are in accord within about $0.01^{\circ} \mathrm{C}$ or better. It should be emphasized that 
the downward concavity is a necessary but not a sufficient criterion of equilibrium.

In table 2 are presented data showing the effect of heat transfer upon the reproducibility of the values of the freezing point obtained from freezing curves and of the values obtained from melting curves, and the effect upon the degree of accord of the values from the freezing curves with those from the melting curves. These data, taken with the apparatus described in this paper and with $n$-dodecane containing

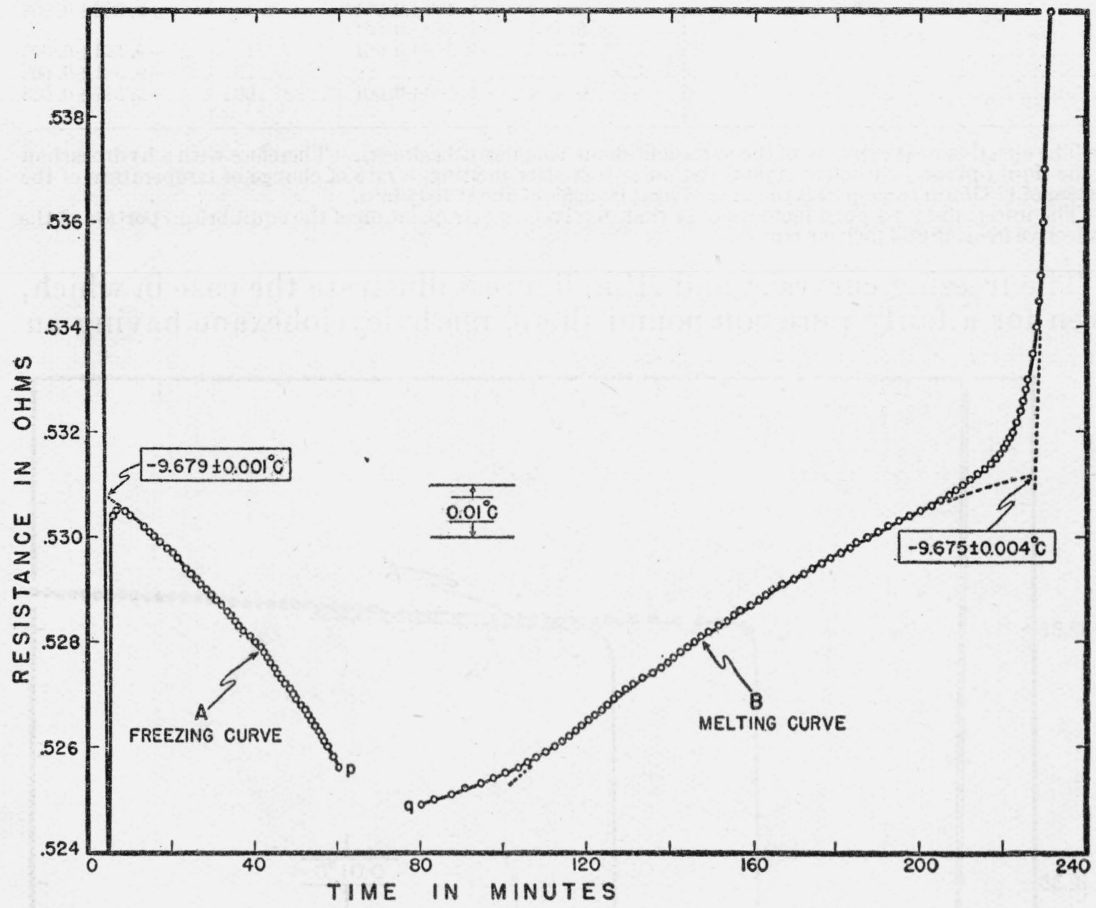

FIGURE 7.-Time-temperature freezing and melting curves for determining the freezing point of a solution of $n$-dodecane containing 0.0062 mole fraction of solute (1,2,4-trimethylcyclohexane).

The scale of ordinates gives the resistance of the platinum thermometer in ohms $\left(0.1 \mathrm{ohm} \approx 1^{\circ} \mathrm{C}\right)$. The scale of abscissae gives the time in minutes. The circles about the observed points are drawn with radii equal to $0.0005^{\circ}$ C. See the text on p. 609 .

0.0012 mole fraction of impurity, show that (a) the value of the freezing point obtained from the freezing curves is substantially independent of the rate of heat transfer for the nearly fourfold increase from 0.4 to $1.5^{\circ} \mathrm{C} / \mathrm{min}^{12}$; (b) the value of the freezing point obtained from the melting curves is significantly affected by the rate of heat transfer, the value obtained increasing with increase in the rate of heat transfer; (c) the most reliable value of the freezing point for this nearly pure substance is that obtained from the freezing curves.

\footnotetext{
${ }^{12}$ See footnote a in table 2.
} 
TABLE 2.-Data showing the effect of the rate of heat transfer on the value of the freezing point determined on a lot of $n$-dodecane containing 0.0012 mole fraction of impurity, as obtained both from freezing and melting curves

\begin{tabular}{|c|c|c|c|c|}
\hline \multirow[b]{2}{*}{ Experiment } & \multicolumn{2}{|c|}{ Freezing part } & \multicolumn{2}{|c|}{ Melting part } \\
\hline & $\begin{array}{c}\text { Rate prior to } \\
\text { crystalliza- } \\
\text { tion } \mathbf{~}\end{array}$ & $\begin{array}{l}\text { Freezing point } \\
\text { determined } b\end{array}$ & $\begin{array}{l}\text { Rate after } \\
\text { melting }{ }^{\text {a }}\end{array}$ & $\begin{array}{c}\text { Freezing point } \\
\text { determined } \mathbf{b}\end{array}$ \\
\hline $\begin{array}{l}1 \\
2 \\
3 \\
4 \\
5\end{array}$ & $\begin{array}{c}{ }^{\circ} \mathrm{C} / \min \\
1.4 \\
0.45 \\
1.5 \\
0.4\end{array}$ & $\begin{array}{c}{ }^{\circ} C \\
-9.590 \pm 0.001 \\
-9.589 \pm 0.001 \\
-9.589 \pm 0.001 \\
-9.590 \pm 0.001\end{array}$ & $\begin{array}{c}\circ C / \min \\
0.1 \\
.1 \\
.25 \\
.004\end{array}$ & $\begin{array}{c}{ }^{\circ} C \\
-9.582 \pm 0.008 \\
-9.584 \pm 0.005 \\
-9.581 \pm 0.008 \\
-9.587 \pm 0.003\end{array}$ \\
\hline
\end{tabular}

s The effective heat capacity of the system is about $100 \mathrm{j} / \mathrm{deg}(24 \mathrm{cal} / \mathrm{deg})$. Therefore with a hydrocarbon in the liquid phase just before crystallization or just after melting, a rate of change of temperature of the system of $1^{\circ} \mathrm{C} / \mathrm{min}$ corresponds to a rate of heat transfer of about $100 \mathrm{j} / \mathrm{min}$.

$b$ The uncertainty assigned includes only that involved in extrapolation of the equilibrium portion of the respective freezing and melting curves.

The freezing curves $A$ and $A^{\prime}$ in figure 8 illustrate the case in which, even for a fairly pure compound (here, methylcyclohexane having an

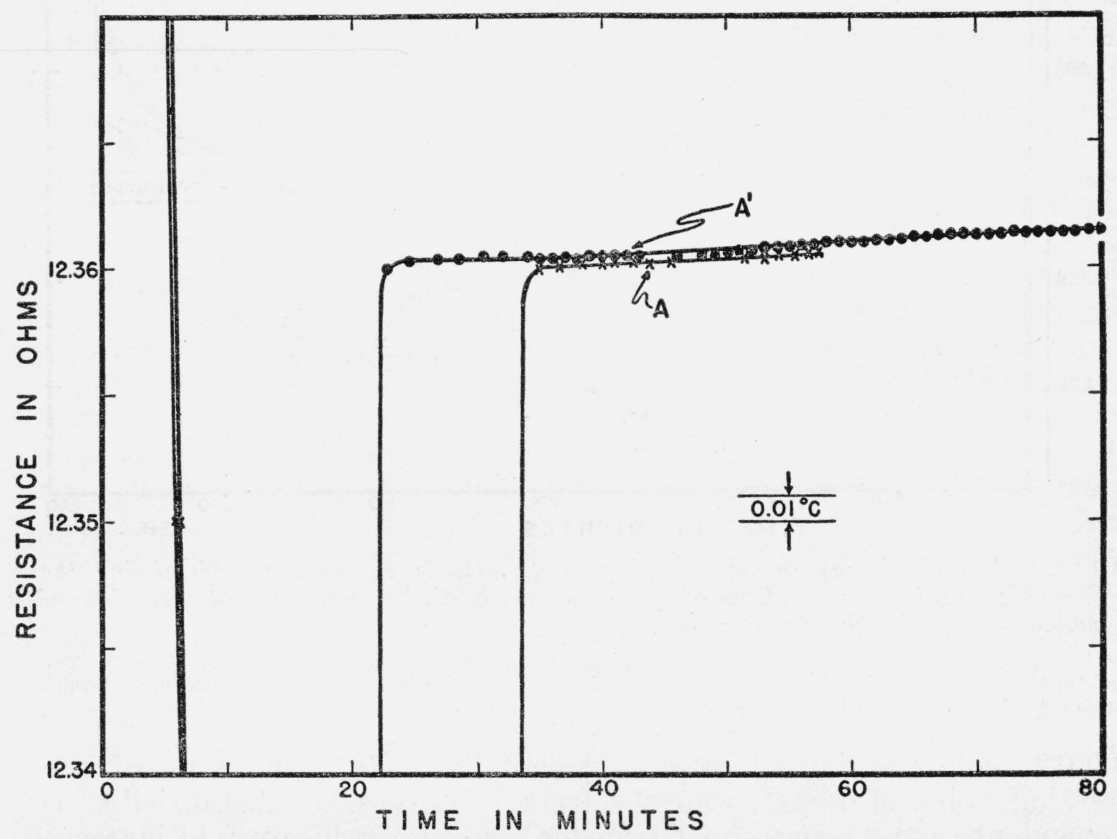

FIGURE 8.-Time-temperature freezing curves illustrating a case of nonequilibrium.

The scale of ordinates gives the resistance in ohms of the platinum resistance thermometer $0.1 \mathrm{ohm} \approx$ $1^{\circ} \mathrm{C}$ ) and the scale of abscissae gives the time in minutes. The two freezing curves were obtained on a sample of methylcylcohexane containing about 0.005 mole fraction of impurity. See the text on p. 612-13 for explanation.

impurity of about 0.005 mole fraction), the extent of undercooling, or the abnormal crystallizing behavior, or both, is so great as to render invalid, as far as thermodynamic equilibrium is concerned, the part of the freezing curve that, with stirring, is normally the portion representing thermodynamic equilibrium. It will be noticed that no portion 
of these curves is concave downward. Instead, even $70 \mathrm{~min}$ after the onset of crystallization, the temperature is still rising. The curve $A^{\prime}$ was obtained from an experiment repeating that from which curve $A$ was obtained, with the hydrocarbon having been kept at a temperature always below $-80^{\circ} \mathrm{C}$ during the intervening period of 1 day, and with seeding with a cold wire in order to induce crystallization during the freezing period and to reduce the extent of undercooling..$^{13}$ It will be noticed that the characteristics of this curve are no better than those of curve $A$. The only conclusion which can be drawn from such curves is that the freezing point is higher than the highest temperature observed after crystallization begins. In such cases, the proper value of the freezing point must be determined from time-temperature melting curves.

In table 3 are presented data showing the results of determinations of the values of the freezing point, obtained both from freezing and melting curves, for several hydrocarbon systems containing known amounts of solute. There are also included in the table values of the freezing point calculated for the corresponding ideal solutions by means of eq 1. The three substances used as the main components were lots of 2,2,4-trimethylpentane, $n$-dodecane, and toluene. These were found to contain impurities in the amount of $0.0018,0.0012$, and 0.0005 mole fraction, respectively, as determined by the method described in section II-3 of this paper. The freezing points for samples containing zero mole fraction of impurity were calculated by correcting the freezing points determined for these actual samples for the lowering caused by the given small amount of impurity, by means of eq 1. For the several solutions, the original amount of impurity in the main component was included with the amount of known solute added to obtain the total concentration of solute. It may be noted that the values of the freezing point determined from the freezing curves and from the melting curves are in excellent accord, where both were determined. Also, the accord of these values with those calculated for ideal solutions of the same concentration indicates that, over these ranges of concentration, such hydrocarbon systems are substantially ideal, or are ones in which the fugacity of the solute is proportional to its mole fraction. In these calculations, the following auxiliary data were used: for 2,2,4-trimethylpentane, $\Delta H_{f_{0}}=2201.6$ $\mathrm{cal} / \mathrm{mole}$ and $\Delta C_{p}=7.1 \mathrm{cal} / \mathrm{mole}$, from Pitzer [14]; for $n$-dodecane, $\Delta H_{f_{0}}=8,743 \mathrm{cal} / \mathrm{mole}$ and $\Delta C_{p} 13.45 \mathrm{cal} / \mathrm{mole}$, from Huffman, Parks, and Barmore [11]; for toluene, $\Delta H_{f_{0}}=1,580 \mathrm{cal} / \mathrm{mole}$ from Parks and Huffman [12], and $\Delta C_{p}=7 \mathrm{cal} / \mathrm{mole}$, estimated; $R=1.98714 \mathrm{cal} / \mathrm{deg}$ mole and $0^{\circ} \mathrm{C}=273.16^{\circ} \mathrm{K}[13,20]$.

\footnotetext{
${ }^{13}$ It has been observed by a number of investigators in this and other laboratories that (a) seeding with crystals and (b) maintaining the hydrocarbon for an appreciable time at a temperature just below its freezing point serve to facilitate the formation of crystals. Sec also [10].
} 
TABLE 3.-Values of the freezing points of known solutions of hydrocarbons, determined both from freezing and melting curves

\begin{tabular}{|c|c|c|c|c|c|}
\hline \multicolumn{3}{|c|}{ Solution } & \multicolumn{2}{|c|}{$\begin{array}{l}\text { Freezing point of the } \\
\text { solution }\end{array}$} & \multirow{2}{*}{$\begin{array}{l}\text { Freezing } \\
\text { point of } \\
\text { the ideal } \\
\text { solution }\end{array}$} \\
\hline Main component & Solute added & $\begin{array}{l}\text { Concentra- } \\
\text { tion of total } \\
\text { solute }\end{array}$ & $\begin{array}{l}\text { From the } \\
\text { freezing } \\
\text { curve }^{\mathrm{a}}\end{array}$ & $\begin{array}{l}\text { From the } \\
\text { melting } \\
\text { curve }\end{array}$ & \\
\hline 2,2,4-Trimethylpentane & \multirow[b]{2}{*}{$\begin{array}{l}n \text {-Heptane } \\
\text { do } \\
\text { Methylcyclohexane } \\
\text { do } \\
\text { do }\end{array}$} & \multirow{2}{*}{$\begin{array}{r}\text { Mole fraction } \\
0.0000 \\
\\
.0018 \\
.0113 \\
.0113 \\
.0266 \\
.0266 \\
.0727 \\
.1147\end{array}$} & $\begin{array}{c}{ }^{\circ} C \\
(-107.347)\end{array}$ & ${ }^{\circ} \mathrm{C}$ & $\begin{array}{c}{ }^{\circ} \mathrm{C} \\
(-107.347)\end{array}$ \\
\hline  & & & $\begin{array}{l}-107.394 \\
-107.640 \\
-107.643 \\
-108.015 \\
-108.005 \\
-109.18 \\
-110.32\end{array}$ & $\begin{array}{r}-107.638 \\
-108.010 \\
-110.32 \\
\end{array}$ & \multirow{2}{*}{$\begin{array}{l}-107.629 \\
-107.629 \\
-108.014 \\
-108.014 \\
-109.20 \\
-110.32 \\
(-9.570)\end{array}$} \\
\hline$n$-Dodecane.. & & .0000 & $(-9.570)$ & \multirow{3}{*}{$\begin{array}{l}-9.587 \\
-9.676\end{array}$} & \\
\hline $\begin{array}{l}\text { Do.- } \\
\text { Do.. }\end{array}$ & \multirow{2}{*}{$\begin{array}{l}\text { 1,2,4-trimethylcyclohex- } \\
\text { ane. }\end{array}$} & \multirow{4}{*}{$\begin{array}{l}.0000 \\
.0005 \\
.0125\end{array}$} & $\begin{array}{l}-9.589 \\
-9.679\end{array}$ & & \multirow{3}{*}{$\begin{array}{r}-9.668 \\
-9.668 \\
(-94.983)\end{array}$} \\
\hline Do. - & & & -9.678 & & \\
\hline $\begin{array}{l}\text { Toluene.- } \\
\text { Do }\end{array}$ & & & $\begin{array}{c}(-94.983) \\
-95.005\end{array}$ & & \\
\hline & $m$-Xylene & & & -95.511 & -95.492 \\
\hline
\end{tabular}

a The values in parentheses for zero mole fraction of impurity were obtained by correcting, with the aid of eq 1, the freezing points of the actual samples for the lowering caused by the small amounts of impurity they contained.

\section{ESTIMATION OF THE AMOUNT OF IMPURITY}

In the experimental determination of the amount of impurity by the procedures outlined in section II-3 and with an apparatus similar to that described in section III-1, there exist a number of factors whose influence cannot be evaluated quantitatively and which may contribute significant uncertainties in the estimation of the amount of impurity. These factors include (a) change in volume of the substance on crystallization, (b) accumulation of solid substance on the walls of the container during crystallization, (c) nonuniformity of temperature throughout the substance after cessation of stirring, (d) change in the energy of stirring, (e) incomplete crystallization of the substance, (f) difference in heat of fusion between the impurity and the major component, and $(\mathrm{g})$ inclusion of solute within the crystals of the major component. Of these factors, all but (f) are ones whose influence may be altered by appropriate change in the experimental arrangements.

The effect of the change in volume of the substance as it passes from the liquid to the solid state is to change the rate of heat transfer between the container and the jacket. For hydrocarbons, the change in volume from liquid to solid is negative, so that the rate of heat transfer will decrease as the crystallization proceeds. If that part of the wall of the container which is touched by the hydrocarbon has a value for the thermal conductivity approaching zero, the rate of heat transfer across the insulating jacket will be approximately directly proportional to the area touched by the hydrocarbon. On the other hand, if the value for the thermal conductivity of the same part of the inner wall of the container approaches infinity, the change in volume of the hydrocarbon will have no effect on the rate of heat transfer. 
For most hydrocarbons, the decrease in volume on crystallization is about 5 to 10 percent. Assuming the most unfavorable case, where the rate of heat transfer will change directly with change in volume, and where the change in volume is 10 percent, the effect is to make the calculated amount of impurity too large by about 4 percent when $T_{z_{0}}-T_{z}$ is measured at one-fourth the total time of crystallization, and about $2 \frac{1}{2}$ percent when $T_{z_{0}}-T_{z}$ is measured at one-half the total time. Actually, the error from this source must be less than this because the thermal conductivity of the glass wall is several times that of the hydrocarbon in either the liquid or solid state. The error from this source may be reduced by placing within the freezing tube a closefitting cylindrical tube of high thermal conductance of such length that it extends above the surface of the liquid substance but well below the level of the refrigerant.

The effect of the accumulation of solid substance on the walls of the container during crystallization, particularly after the cessation of stirring, is to decrease the over-all heat-transfer coefficient, and hence to lengthen the time of crystallization and make the estimated amount of impurity too large. However, as already mentioned, a decrease in the rate of crystallization of 10 percent from the initial to the final time of crystallization will have a much smaller percentage effect on the estimated amount of impurity. If the heat-transfer coefficient of the space between the substance and the jacket approaches that of the hydrocarbon in value, there will be a very significant change in the over-all rate of transfer of heat, and hence in the rate of crystallization, as the liquid hydrocarbon solidifies. If, however, the heat-transfer coefficient of the space between the substance and the jacket is very small in comparison with the heat-transfer coefficient of the hydrocarbon, there will be only a very small change in the over-all heattransfer coefficient as the hydrocarbon solidifies and hence only a very small change in the rate of crystallization. The use of an insulating space having a very small heat-transfer coefficient, as provided by a silvered and well-evacuated vacuum flask, will reduce the error from this source. That is to say, a given rate of heat transfer between the substance and jacket should be obtained by using an insulating space with a low heat-transfer coefficient and an appropriate head of temperature.

Nonuniformity of temperature throughout the substance after cessation of stirring during the freezing experiment, from which time the temperature of that part of the substance around the thermometer is higher than that at the walls of the container, may influence the results in two ways. The correction for changing thermal head described in section II-3 is based on an ideal curve in which uniformity of temperature within the system is assumed. In the case of nonuniformity of temperature within the freezing tube, the rate of transfer of energy from the substance as a whole depends on the difference in temperature between the inner wall of the tube and the refrigerant rather than the difference in temperature between the thermometer and the refrigerant. In other words, the area above any actual curve, customarily used in correcting for change in thermal head, is not quite as large as the corresponding area above an ideal curve. Since the total correction for changing thermal head is large only in the case of small thermal heads and impure solutions, this part of the effect of 
nonuniformity of temperature must be practically negligible in almost all cases. In the extrapolation (described in section II-3) which is made to take care of the fact that a portion of the energy transferred is used not in the crystallization, but in cooling the solid to the final temperature, the assumption of uniformity of temperature is made. If, as is actually the case, the temperature recorded is higher than the mean temperature of the solid, it is evident that additional energy has been transferred (and time elapsed) in cooling the solid below the recorded temperature. In other words, the value estimated for the total time is too long, which yields too large a value for the amount of impurity. To reduce the importance of this effect of nonuniformity of temperature, the stirrer may be made of a material of high thermal conductivity and designed so as to have sufficiently thick vanes traversing the substance. Keeping the thermal conductivity of the insulating jacket very small in comparison with the thermal conductivity of the substance also reduces the magnitude of the effect.

To take account of the fact that stirring energy is contributed to the substance only during the first part of the crystallization, a correction to the time of crystallization is described in section II-3. In making this correction, it is assumed that the energy of stirring is constant over the time the stirrer is in operation and equal to the value it has when the material is all in the liquid state. Since in the actual experiment, the stirrer is operated until one-fifth to one-third of the substance has crystallized, it is obvious that the presence of the solid material will increase the stirring resistance, and hence the rate of evolution of energy by stirring will be greater at the time of cessation of stirring than at the time crystallization is just beginning. The correction for stirring is, therefore, smaller than it should be. By using a stirrer that clears the inner wall of the container by several millimeters, and by stopping the stirrer as soon as a sufficient portion of the equilibrium freezing curve is obtained, the effect of change in the rate of evolution of energy by stirring may be minimized. In the experiments described in this paper, the stirring energy is about 2 percent of the total rate of transfer of heat between the substance and the jacket during freezing. In general, it is advisable to have the amount of stirring great enough to produce thorough mixing of the liquid and crystalline phases during the given period, but not so large as to be more than several percent of the total rate of transfer of heat.

Incomplete crystallization of the substance may occur in those cases where the impurity consists of one or more components having low freezing points, or where the impurity consists of a large number of components having freezing points below, or not far above, that of the major component, if the observations are not taken well below the temperature at which the last of these components of the impurity has crystallized out in the form of a eutectic with the major component. In such cases, when the amount of impurity is large and when the heat of fusion of the major component is small, a significant amount of the substance may remain uncrystallized even at temperatures $50^{\circ}$ $\mathrm{C}$ or more below the normal freezing point of the major component. The total time of crystallization deduced from such observations will be too small, not only because some of the substance has not yet crystallized, but also because the slope of the "solid" line will indicate a rate of decrease of temperature not quite large enough. To reduce this error, which leads to too small a value for the amount of impurity, 
it is necessary to use a large head of temperature between the substance and the jacket to permit observations to be taken to temperatures $75^{\circ} \mathrm{C}$ or more below the freezing point of the major component. For substances containing several mole percent of impurity, the foregoing is likely to be the source of greatest error.

The effect of a difference in heat of fusion between the impurity and the major component is to change the relation between the mole fraction of impurity in the liquid phase and the time of crystallization as given by eq 9 . When the heat of fusion of the impurity is less than that of the major component, the observed time of crystallization is smaller than it would be with no difference in heat of fusion, and the effect is to make the estimated amount of impurity too small. When the heat of fusion of the impurity is larger than that of the major component, the effect is to make the estimated amount of im-

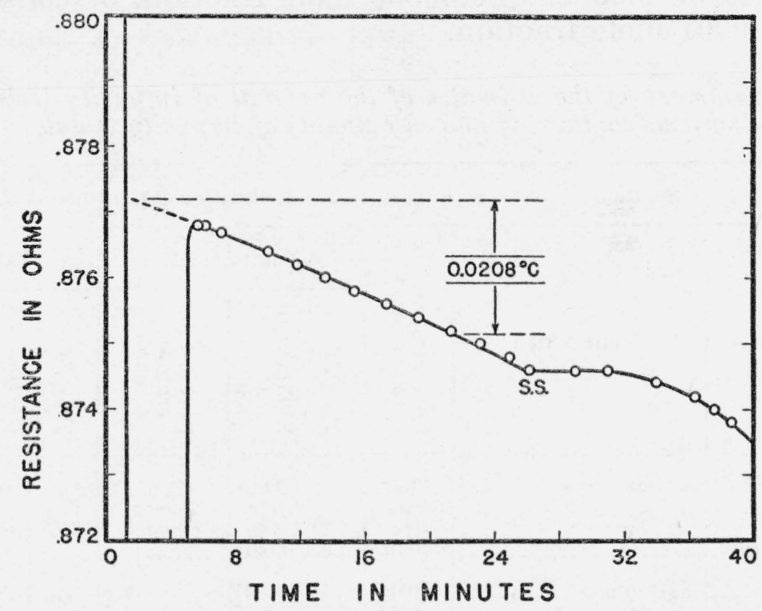

FIGURE 9.-Part of a time-temperature freezing curve illustrating the sensitivity of the method.

The scale of ordinates gives the resistance in ohms of the platinum resistance thermometer $\left(0.1\right.$ ohm $\approx 1^{\circ}$ C). The scale of abscissae gives the time in minutes. These observations were made on a lot of 1,2,3,4tetramethylbenzene having an amount of impurity estimated to be $0.0006 \pm 0.0001$ mole fraction. The circles are drawn with radii equal to $0.0005^{\circ} \mathrm{C}$.

purity too large. When the amount of impurity is 0.01 mole fraction or less, the error from this source is usually negligible.

The effect of the inclusion of solute within the crystals of the major component is to raise the equilibrium portion of the freezing curve and consequently to yield too small a value for the amount of impurity.

The best criterion of the over-all effect of these uncertainties on the value of the amount of impurity estimated is that of making observations on known systems and comparing the estimates of impurity with the amounts actually present. The results of such comparisons are given in table 4, where the amounts of impurity estimated from time-temperature curves in the manner described on pages 599-602 in section II-3 are compared with the actual amounts known to be present in the given solutions. The six different solutions investigated were made from three main components and four different solutes, and the concentrations range from 0.0062 to 0.1147 mole fraction. Eight different results are listed because two independent time-tem- 
perature curves were obtained on each of two systems. In seven of the experiments, the period of equilibrium extended far enough for the fraction crystallized to be taken as one-third, but, in one experiment, the period of equilibrium did not extend beyond the time when about one-fifth of the material was crystallized. From the results obtained, it appears that the amount of impurity can be estimated with an uncertainty not greater than about 10 percent of itself.

The sensitivity of this method and procedure for estimating the amount of impurity is illustrated by some observations made on 1,2,3,4-tetramethylbenzene isolated from petroleum [19]. In figure 9 is shown part of a complete freezing curve obtained with this substance. From the indicated lowering of temperature, which was measured from the initial time to the time when one-third of the material had crystallized, the amount of impurity in the original substance was calculated to be $0.00058 \pm 0.00006$ mole fraction, or conservatively, $0.0006 \pm 0.0001$ mole fraction.

TABLE 4.-Summary of the estimates of the amount of impurity (solute) made on systems containing known amounts of impurity (solute)

\begin{tabular}{|c|c|c|c|c|c|c|c|c|}
\hline \multicolumn{3}{|c|}{ Solution } & \multicolumn{6}{|c|}{ Estimation of the amount of impurity } \\
\hline \multirow[b]{2}{*}{ Main component } & \multirow[b]{2}{*}{ Solute added } & \multirow{2}{*}{  } & \multicolumn{3}{|c|}{ Taking $r=1 / 3$} & \multicolumn{3}{|c|}{ Taking $r=1 / 5$} \\
\hline & & & $\begin{array}{l}\text { E-1 } \\
1 \\
\text { E } \\
\text { I }\end{array}$ & 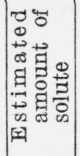 & 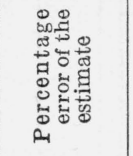 & 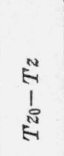 & 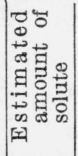 & 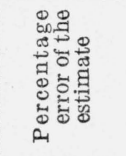 \\
\hline \multirow{6}{*}{$\begin{array}{l}\text { 2,2,4-Trimethylpen- } \\
\text { tane. } \\
\text { Do } \\
\text { Do } \\
\text { Do.-. } \\
\text { Do } \\
\text { Do } \\
\text { Do }-\end{array}$} & & $\begin{array}{c}\text { Mole } \\
\text { frac- } \\
\text { tion } \\
(0.0018)\end{array}$ & $\begin{array}{l}\circ C \\
0.023\end{array}$ & $\begin{array}{c}\text { Mole } \\
\text { frac- } \\
\text { tion } \\
0.0018\end{array}$ & $\begin{array}{l}\text { \% of } \\
\text { known } \\
\text { amount }\end{array}$ & ${ }^{\circ} \mathrm{C}$ & $\begin{array}{l}\text { Mole } \\
\text { frac- } \\
\text { tion }\end{array}$ & $\begin{array}{c}\% \text { of } \\
\text { known } \\
\text { amount }\end{array}$ \\
\hline & $n$-Heptane & .0113 & .140 & .0111 & $\begin{array}{r}-1.8 \\
+3.5\end{array}$ & & & \\
\hline & Methylcyclohexane & .0266 & .368 & .0286 & $\begin{array}{r}0.0 \\
+7.0\end{array}$ & 0.174 & 0.0272 & +2.3 \\
\hline & -.... do do & .0266 & .334 & .0261 & -1.9 & .171 & .0268 & +0.8 \\
\hline & -...-do do & .072 & .977 & .0726 & -0.1 & .480 & .0718 & -1.2 \\
\hline & $-\cdots$ & .11 & & .0000 & -14.1 & .030 & .1010 & -12 \\
\hline $\begin{array}{l}n \text {-Dodecane } \\
\text { Do }\end{array}$ & $\begin{array}{l}\text { 1,2,4-Trimethihy leyclo- } \\
\text { hexane. }\end{array}$ & $\begin{array}{l}(.0012) \\
.0062\end{array}$ & & & & $\begin{array}{l}.005 \\
.027\end{array}$ & $\mid \begin{array}{l}.0012 \\
.0068\end{array}$ & +9.7 \\
\hline \multirow{2}{*}{ Toluene. } & & $(.0005)$ & .010 & .0005 & & & & \\
\hline & $m$-Xylene & .0126 & .246 & .0121 & -4.0 & & $\cdots$ & \\
\hline \multicolumn{5}{|c|}{ Mean value of the percentage error } & $\mathrm{b}-(1.6 \pm 5.0)$ & & & $\mathrm{b}-(0.1 \pm 7$ \\
\hline
\end{tabular}

a Values in parentheses refer to the original samples which were used to prepare the various solutions. The impurity was taken as equal to that estimated from the time-temperature cooling curves.

b The uncertainty assigned here is twice the standard deviation. See [17].

\section{CONCLUSION}

The following points should be noted in connection with the procedure and discussion presented in this paper:

1. The procedure described for determining the freezing point and estimating the amount of impurity may be used only when the given substance crystallizes in such a way as to produce a freezing curve, a melting curve, or both, of which, in each case, a known portion represents thermodynamic equilibrium between the liquid and 
crystalline phases. In this connection, the possibility must not be overlooked of the existence of a metastable equilibrium between the undercooled liquid and a crystal phase different from that which exists at the normal freezing point. See, for example, [9, p. 466].

2. While the lowering of the freezing point measures only the liquid-soluble, solid-insoluble impurity, this will represent substantially all of the impurity for the hydrocarbons obtained from petroleum, because the cases in which solid solutions occur in such systems are relatively rare. (See, for example, the work of Smittenberg, Hoog, and Henkes [15], who investigated a number of binary systems of such hydrocarbons and reviewed the earlier work in this field.) Further, any rational method of purification will leave in a given hydrocarbon only impurities that are very much like it in properties, and that, hence, will tend to form an ideal solution with it. For example, in the hydrocarbons separated from petroleum, the impurities most likely to remain in a given compound after purification will be aromatic impurities in an aromatic hydrocarbon, naphthenic impurities in a naphthene hydrocarbon, paraffinic impurities in a paraffin hydrocarbon. Less likely will be naphthenic impurities in a paraffin hydrocarbon and paraffinic impurities in a naphthene hydrocarbon, and least likely will be aromatic impurities in a paraffin or naphthene hydrocarbon and paraffinic or naphthenic impurities in an aromatic hydrocarbon.

3. From the data presented in table 4, it appears that estimates of the amount of impurity, determined by the procedure discussed in this paper, will be uncertain by not more than about 10 percent of the amount of impurity, for concentrations from about 0.005 to 0.1 mole fraction. For substances containing more than about 0.1 mole fraction of impurity, the uncertainty will very likely be greater, but, on the other hand, the need for the higher certainty on such very impure substances is correspondingly less. For substances containing less than about 0.005 mole fraction of impurity, the uncertainty of the estimates of impurity may be influenced largely by the precision of the measurement of temperature. For example, where the cryoscopic constant $A$ is equal to $1 / 30$ and $r$ is equal to $1 / 4$, values of $T_{z_{0}}-T_{z}$ equal to $0.01^{\circ}, 0.001^{\circ}$, and $0.0001^{\circ} \mathrm{C}$ correspond to values of $N_{2}^{*}$ equal to $0.001,0.0001$, and 0.00001 mole fraction, respectively. With hydrocarbons containing small amounts of impurity (about 0.001 mole fraction or less), it is usually necessary to have a thermometric sensitivity at least as small as $0.001^{\circ} \mathrm{C}$, and to plot the appropriate part of the freezing curve on an expanded scale of temperature, in order to identify the portion of the curve representing thermodynamic equilibrium and to determine the lowering for a given fraction crystallized. For such compounds, departure from thermodynamic equilibrium during freezing frequently begins even before cessation of stirring.

\section{REFERENCES}

[1]. W. P. White, J. Phys. Chem. 24, 393 (1920).

[2.] J. G. Aston and G. H. Messerly, J. Am. Chem. Soc. 62, 1917 (1940).

[3.] J. G. Aston, R. M. Kennedy, and S. C. Schumann, J. Am. Chem. Soc. 62, 2059 (1940).

[4.] W. F. Giauque and R. A. Ruehrwein, J. Am. Chem. Soc. 61, 2626 (1939).

[5.] R. A. Ruehrwein and W. F. Giauque, J. Am. Chem. Soc. 61, 2940 (1939). 
[6.] F. W. Schwab and E. Wichers, Temperature-Its Measurement and Control in Science and Industry, p. 256-264 (Reinhold Publishing Corp., New York, N. Y., 1941).

[7.] E. W. Washburn, J. Am. Chem. Soc. 32, 653 (1910).

[8.] G. N. Lewis and M. Randall, Thermodynamics and the Free Energy of Chemical Substances (McGraw-Hill Book Co., New York, N. Y., 1923).

[9.] B. J. Mair, BS J. Research 9, 457 (1932) RP482.

[10.] J. H. Bruun, M. M. Hicks-Bruun, and W. B. M. Faulconer, J. Am. Chem. Soc. 59, 2355 (1937).

[11.] H. M. Huffman, G. S. Parks, and M. Barmore, J. Am. Chem. Soc. 53, 3876 (1931).

[12.] G. S. Parks and H. M. Huffman, Ind. Eng. Chem. 23, 1138 (1931).

[13.] F. D. Rossini, J. Research NBS 22, 407 (1939) RP1192.

[14.] K. S. Pitzer, J. Am. Chem. Soc. 62, 1224 (1940).

[15.] J. Smittenberg, H. Hoog, and R. A. Henkes, J. Am. Chem. Soc. 60, 17 (1938).

[16.] J. W. Williams and F. Daniels, J. Am. Chem. Soc. 46, 915 (1924).

[17.] F. D. Rossini and W. E. Deming, J. Wash. Acad. Sci. 29, 416 (1939).

[18.] F. D. Rossini, J. Research NBS 11, 553 (1933) RP607.

[19.] B. J. Mair and A. J. Streiff, A. P. I. Research Project 6 at the National Bureau of Standards. Work in progress.

[20.] H. T. Wensel, J. Research NBS 22, 375 (1939) RP1189.

Washington, March 13, 1941. 